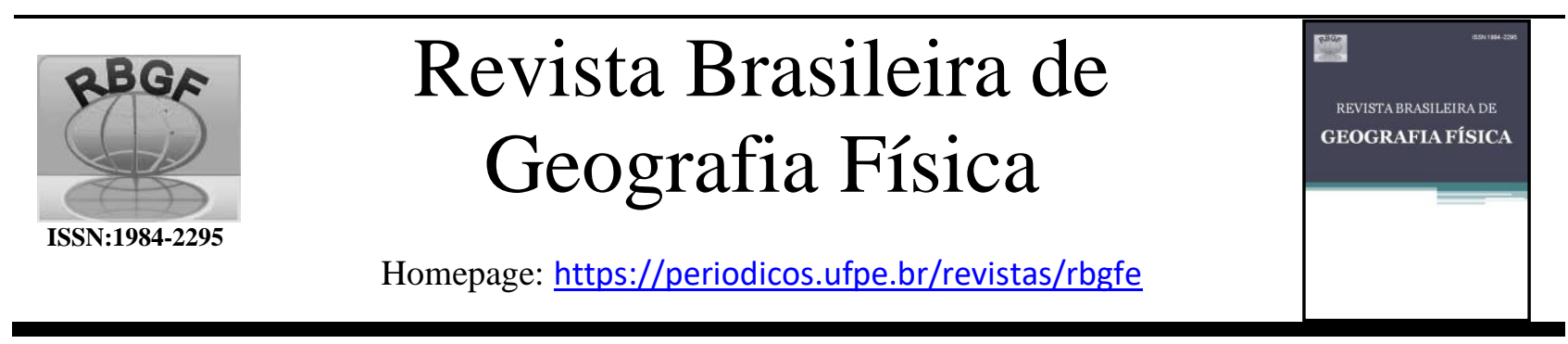

\title{
Dinâmica da Paisagem e seus Impactos Ambientais na Amazônia
}

\author{
Flávio Augusto Altieri dos Santos ${ }^{1}$, Edson José Paulino da Rocha ${ }^{2}$, Josiane Sarmento dos Santos ${ }^{3}$
}

\begin{abstract}
1 Analista em Ciência e Tecnologia do Centro Gestor e Operacional do Sistema de Proteção da Amazônia - Censipam, E-mail: flavio.santos@sipam.gov.br. ${ }^{2}$ Prof. Dr. da Universidade Federal do Pará. ${ }^{3}$ Doutoranda do Programa de Pós-Graduação em Ciências Ambientais da Universidade Federal do Pará
\end{abstract}

Artigo recebido em 30/09/2018 e aceito em 25/01/2019

\section{R E S U M O}

Este estudo analisa os impactos ocasionados pela ação antrópica na bacia do rio Xingu e nas sub-bacias dos rios Fresco, Curuá e Ronuro, em diferentes escalas para o período de 2004 a 2014. O objetivo é avaliar temporalmente o processo de uso e ocupação do solo e seus impactos nos padrões da paisagem, com intuito de subsidiar estudos sobre possíveis alterações na resposta hidrológica de bacias hidrográficas. Os padrões da paisagem foram analisados a partir da estrutura fundiária da bacia com base nas áreas especialmente protegidas e nos imóveis rurais certificados. Os padrões da paisagem foram analisados tendo como referência as métricas geradas pelo software FRAGSTATS 4.2 e os dados do mapeamento das modificações do uso e ocupação do solo elaborado pelo projeto TerraClass do INPE. O resultado da análise da estrutura fundiária mostra que as áreas especialmente protegidas contribuem para conter, parcialmente, o avanço do desmatamento sobre paisagem original preservada, e que existe uma elevada concentração de área em terras privadas classificadas como latifúndios. Os padrões da paisagem indicam um comprometimento das manchas de floresta consequência do avanço da atividade produtiva, mas que também, observa-se um comprometimento das métricas analisadas das outras classes. Com isso conclui-se que a bacia do rio Xingu e as 3 sub-bacias estudadas podem vir ter a resposta hidrológica afetada, principalmente, a sub-bacia do rio Curuá, casos os avanços da atividade produtiva progridam sobre as manchas de florestas.

Palavras-Chaves: Uso e ocupação do solo, estrutura fundiária, métrica de paisagem, bacia hidrográfica.

\section{Dynamics of Landscape and its Environmental Impacts in the Amazon}

\begin{abstract}
A B S T R A C T
This study analyzes the impacts caused by anthropogenic action in the Xingu basin and in the sub-basins of the rivers Fresco, Curuá and Ronuro, in different scales for the period from 2004 to 2014. The objective is to evaluate temporarily the process of use and occupation of the soil and its impacts on landscape patterns, with the aim of supporting studies on possible alterations in the hydrological response of river basins. Landscape patterns were analyzed from the basin's land structure based on specially protected areas and certified rural properties. The landscape patterns were analyzed with reference to the metrics generated by the FRAGSTATS TM 4.2 software and the data of the mapping of land use and land use modifications prepared by the INPE TerraClass project. The result of the analysis of the land structure shows that the specially protected areas contribute to partially contain the advance of deforestation on preserved original landscape, and that there is a high concentration of area in private lands classified as latifundia. The landscape patterns indicate a deterioration of forest patches as a consequence of the advance of the productive activity, but also, a reduction in the majority of the analyzed metrics is observed. With this, it can be concluded that the Xingu basin and the 3 sub-basins studied may have a hydrological response, mainly in the Curuá River sub-basin, in which cases the progress of the productive activity progresses on forest patches.
\end{abstract}

Keywords: Land use and occupation, land structure, landscape metric, hydrographic basin. 


\section{Introdução}

A Amazônia brasileira vem vivenciando ao longo das décadas, intenso processo de transformação das suas paisagens (destruição e degradação da floresta superior a $60 \%$ de sua cobertura) que têm repercussão nas mudanças climáticas (Nobre, 2014 p. 24). Becker (1990) afirmava que as políticas de desenvolvimento para a Amazônia promoveram a degradação da floresta e dos solos desta região. Entre as alterações ocorridas, se destacam as mudanças na cobertura florestal pristina que aconteceram pela ação antrópica presente, principalmente, na área de influência da rodovia Transamazônica (BR-230) e suas vicinais, cuja ocupação humana vem sendo induzida por projetos de colonização agrária nos últimos 45 anos. O processo de ocupação da Amazônia ocorreu de forma desordenada e predatória sob a ordem de uma estratégia de integrar para não entregar, alinhada a ideia de desenvolver e ocupar a região com uma estratégia de segurança nacional (Silva et al., 2015). Fearnside (2001) registra que as grandes plantações de sojas estavam ocupando o norte do Mato Grosso a partir das áreas de cerrado, enquanto que a parte sul e leste do Pará o predomínio era das grandes propriedades de pecuária.

Estudos indicam que o processo de mudança de uso e cobertura da terra resulta em vários impactos sobre a paisagem. Costa et al. (2015) afirma que a perda da floresta nativa, aumenta o número de fragmentos e as distâncias entre os mesmos, com isso ocorre uma diminuição da conectividade. Simulações de uso e cobertura da terra realizada por Nobrega (2014) indicaram aumento no escoamento superficial quando ocorre desmatamento, ocasionado pela redução da interceptação da água pelo dossel. Outro problema advindo das alterações na cobertura floresta está relacionado com a variabilidade da precipitação em escala local e regional (Khanna et al., 2017; Spera et al., 2016), afetando diretamente as descargas dos rios. As alterações decorrentes do desmatamento também podem promover mudanças expressivas nas vazões das bacias hidrográficas, provocando impactos generalizados sobre os demais recursos naturais (Gyawali; Greb; Block, 2015; Rice et al., 2015; Souza-Filho et al., 2016).

Os estudos realizados por Hamilton (1990) e Wilk et al. (2001), indicam que o impacto da mudança do uso do solo nas descargas observadas diminui com o tamanho da bacia, e que a relação entre a resposta hidrológica da bacia e a mudança do uso do solo só ocorrem em bacias menores, enquanto que nas bacias maiores a resposta hidrológica é dependente principalmente da variabilidade da precipitação.

A contraposição e contradição de ideias que ocorrem a partir das interações entre as condições naturais $\mathrm{e}$ as atividades produtivas determinam os princípios metodológicos da investigação geográfica. Desta maneira, técnicas de análise espacial têm sido bastante utilizadas como ferramenta de interpretação dos índices espaciais utilizados em Ecologia da Paisagem, capazes de detalhar a condição da paisagem, na busca do entendimento das conexões relacionadas à biodiversidade os quais não seriam possíveis de serem realizados somente em campo (Souza et al., 2014). É dentro deste contexto que os padrões espaciais das variáveis são relacionados com os processos estudados (Lin et al, 2007).

$\mathrm{Na}$ história da evolução do pensamento geográfico, a paisagem foi analisada por Humboldt, Ritter e Ratzel, onde através da utilização de métodos comparativos e descritivos, eles consideraram a paisagem como o resultado das distribuições e inter-relações entre os componentes e os processos do meio natural, de onde se chegou ao conceito de paisagem natural.

Para a Ecologia da Paisagem "a paisagem é a expressão espacial dos ecossistemas e um complexo, padrão ou mosaico de ecótopos, ou seja, um mosaico de ecossistemas concretos" (Rodriguez: Silva, 2002, p.97). Forman e Godron (1986) definem paisagem como "uma área terrestre heterogênea composta de um grupo de ecossistemas em interação que se repetem de forma semelhante por todo lugar".

Em outras palavras, compreender o funcionamento de uma unidade de paisagem, passa pelo conhecimento dos padrões da fragmentação florestal obtido por meio das métricas da paisagem. Neste contexto, as métricas levam em consideração a quantificação da sua estrutura que permite evidenciar quantidade e qualidade das manchas com base na Ecologia da Paisagem, onde são de grande importância o tamanho do fragmento, a área central, a forma e o grau de seu isolamento (Silva e Souza, 2014).

A análise das métricas de paisagem vem sendo usada para avaliar os padrões da fragmentação florestal, tendo como ponto central, o reconhecimento da dependência espacial entre as unidades de paisagem. Metzger (2001 e 2003) afirma que compreender o funcionamento de uma unidade de paisagem depende das interações com as unidades vizinhas. Tudo isso reforça as afirmações de Cabacinha et al. (2010), que mudanças ocorridas em uma paisagem podem ser 
estudadas por meio da avaliação de índices ou métricas da paisagem para caracterização quantitativa, que permitem também comparar paisagens, identificar diferenças e determinar relações entre os processos funcionais e os padrões dessas paisagens.

Entre os grandes rios que compões a imensa bacia hidrográfica amazônica, o rio Xingu é considerado um dos seus principais afluentes, um rio de águas claras, pobre em sedimentos. Santos et al. (2016) realizaram um estudo sobre a vazão do rio Xingu na cidade de Altamira-PA, nos anos de 1985 a 2013, os autores encontraram valores de pico de vazão máxima em abril $\left(19000 \mathrm{~m}^{3} / \mathrm{s}\right)$ e o mínimo em setembro $\left(1153 \mathrm{~m}^{3} / \mathrm{s}\right)$.

Segundo o Projeto Radam de (1974), devido suas características topográficas, com relevo de variações acentuadas de altitude, o rio Xingu apresenta um grande potencia para uso hidrelétrico. Por conta de ações governamentais equivocadas, a bacia do rio Xingu é a que mais vem sofrendo os efeitos antrópicos da ocupação do solo. O cerrado é a vegetação que vem sofrendo com a expansão da pecuária e do cultivo de soja na parte ao sul da bacia. Na região central, que corresponde ao médio curso, a área é recoberta por florestas ombrófilas, onde manchas de savanas ou contatos savana/floresta ombrófila se destacam em correspondência aos planaltos residuais aí existentes. Ao norte predominam as áreas de floresta ombrófila, grande parte onde estão as áreas intensamente ocupada e alterada.

Desta forma, o objetivo deste estudo foi a análise temporal da dinâmica da paisagem e seus impactos ambientais decorrente do uso e ocupação do solo num período de 10 anos na bacia do rio Xingu de das sub-bacias, a do rio Fresco, Curuá e Runoro, e avaliar a estrutura fundiária nestas áreas e suas possíveis contribuições às condições da paisagem atual.

\section{Material e métodos}

A região de estudo do presente trabalho está relacionada com quatro áreas de diferente escala que são compostas pela bacia do rio Xingu e por três sub-bacias: do rio Fresco na parte leste; do rio Curuá na parte oeste; e, do rio Ronuro localizada no estremo sul (Figura 1).
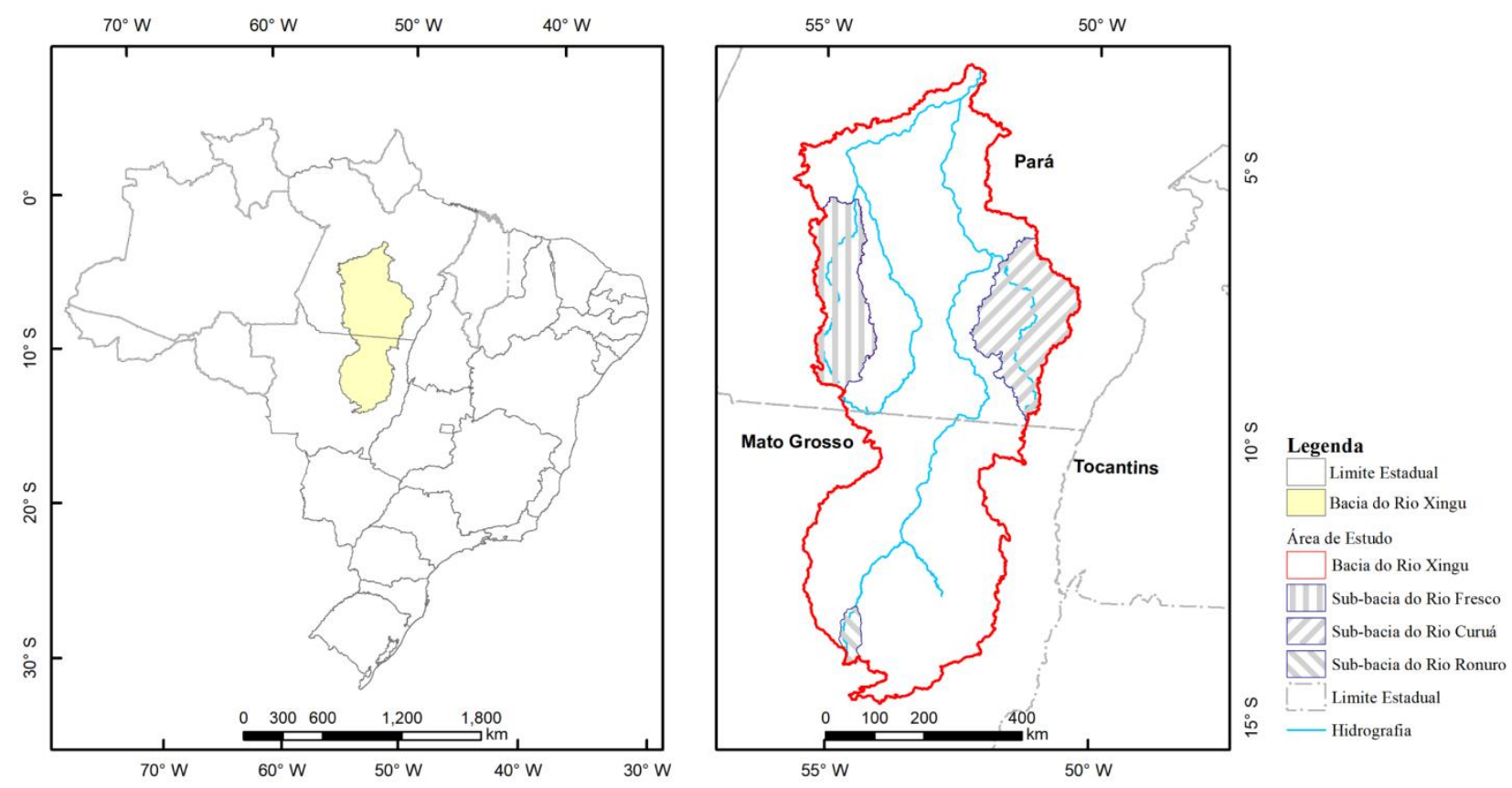

Figura 1. Localização geográfica da bacia do rio Xingu e das sub-bacias dos rios Curuá, Fresco e Ronuro. Fonte: Autor, 2018.

Área de Estudo - a bacia do rio Xingu está localizada na região central do Brasil entre os Estados do Mato Grosso e Pará. As áreas de drenagem da bacia do rio Xingu e das sub-bacias dos rios Fresco, Curuá e Ronuro (Tabela 1), foram delimitadas de modo que seus exutórios coincidissem com a localização das estações fluviométricas da Agência Nacional de Águas (ANA). 
Tabela 1. Área de drenagem e comprimento dos canais de drenagens.

\begin{tabular}{lcrc}
\multicolumn{1}{c}{ Área de Estudo } & $\begin{array}{c}\text { Área de } \\
\text { Drenagem }\left(\mathrm{km}^{2}\right)\end{array}$ & $\begin{array}{c}\text { Canal de Drenagem Principal } \\
(\mathrm{km})\end{array}$ & $\begin{array}{c}\text { Área Especialmente } \\
\text { Protegida }(\%)\end{array}$ \\
\hline Bacia do rio Xingu & 449.222 & $1.528,41$ & 58,5 \\
Sub-bacia rio Fresco & 42.739 & 517,56 & 68,8 \\
Sub-bacia rio Curuá & 35.762 & 532,07 & 57,7 \\
Sub-bacia rio Ronuro & 3.833 & 133,00 & 0,0 \\
\hline
\end{tabular}

Fonte: Elaborado pelo autor, 2018.

$\mathrm{O}$ rio Xingu corre de Sul para Norte e tem cerca de $1.897 \mathrm{~km}$ de extensão desde a nascente até o ponto de desembocadura considerado para a bacia em estudo. As nascentes dos principais rios que compõe a bacia hidrográfica estão localizadas ao norte do Estado de Mato Grosso, no alto Xingu, em região de condições topográfica mais elevada e de clima fortemente estacional, condicionada a vegetação savânica, característica do bioma Cerrado. Já na parte do médio e baixo curso do rio Xingu está presente às extensas áreas de florestas ombrófilas. Essas variações demonstra que se trata de uma região com uma biodiversidade bastante peculiar, resultante do contato entre dois biomas, $\mathrm{o}$ Cerrado e a Floresta Amazônica. A transição observada neste ambiente se traduz pela presença de extensas formações de contato Floresta Ombrófila/Floresta Estacional, esta última característica do limite entre os biomas Amazônia e Cerrado. As Florestas Estacionais em geral apresentam arvores de porte menor que as Ombrófilas, mais adaptadas a se desenvolverem sob duas estações climáticas bem definidas, uma delas com mais de quatro meses de seca por ano.

No alto Xingu, o rio nasce no estado do Mato Grosso, ao norte da região do Planalto Central, na união entre as serras do Roncador e Formosa, aos 600 metros de altitude. Seus principais afluentes nesta área são os rios Ferro (400 km), localizado no lado oriental da Serra Formosa; ao sul, o rio Batovi (330 km); pelo leste, o rio Culuene, de $600 \mathrm{~km}$ de extensão localizado a noroeste da Serra do Roncador; e pelo sudeste, o rio Ronuro $(376 \mathrm{~km})$. No médio Xingu, o rio cruza a divisa do Mato Grosso com o Pará e segue grade parte inserido no município de Altamira, onde recebe pela direita outro de seus principais afluentes, o rio Fresco $(555 \mathrm{~km})$ e pela esquerda o principal afluente é o rio Iriri, de mais de $1.141 \mathrm{~km}$ de extensão e que tem como seu afluente o rio Curuá com $568 \mathrm{~km}$. No trecho do baixo Xingu, o curso do rio passa a ser mais largo e se abre em um lago imenso até encontrar as águas do rio Amazonas.

A supressão da floresta pela agropecuária tem sido o principal vetor de mudança dos padrões da paisagem nas últimas décadas nesta região. As análises dessas modificações ocorridas foram realizadas com base nos dados do INPE, gerados pelo projeto de mapeamento do uso e cobertura da terra na Amazônia Legal Brasileira - TerraClass, produzido a partir da combinação de dados vetoriais de desmatamento do PRODES (INPE 2015) e imagens orbitais por satélite (Landsat-5 / TM, MODIS e SPOT-5) para os anos de 2004, 2008, 2010, 2012 e 2014 (Almeida et al, 2016). Segundo Almeida et al (2016), a classificação do uso e cobertura da terra foi realizada a partir de produtos de alta resolução espacial e temporal, validadas com base nos dados SPOT-5 HRG (Resolução geométrica alta) no modo "panchromatic" (PAN, 0,51 - 0,73 $\mu \mathrm{m}$ ) a uma resolução espacial de $2,5 \mathrm{~m}$.

Para o cálculo das métricas da paisagem foi empregado o pacote de software FRAGSTATS 4.2 (Mcgarigal, 2013) que, por apresentar limitações de processamento devido a extensão da área da bacia e resolução espacial dos dados raster geradas pelo TerraClass (pixel com $30 \mathrm{~m}$ ), os dados foram remostados para um pixel de $90 \mathrm{~m}$, através do método do vizinho mais próximo. Foi realizada também, a reclassificação das 12 classes originais geradas pelo TerraClass para apenas cinco: floresta, atividade produtiva (antropismo), não floresta, vegetação secundária e massa d'água, sendo que está última não foi objeto de análise. As métricas utilizadas foram em nível de classe que estão associadas ao tipo de uso encontrado (Metzger, 2009).

A análise das métricas foi realizada para a bacia do rio Xingu e de maneira individualizada, para três de suas sub-bacias: rio Fresco, Curuá e Ronuro. Neste estudo, foram consideradas as métricas de área: Percentagem da Paisagem por Classe (PLAND), Índice de Maior Mancha (LPI), Densidade de Borda (ED) e Área Média das Manchas (ÁREA-MN); e, as métricas de agregação: Número de Mancha (NP) e Índice de Forma da Paisagem (LSI) conforme descritas na Tabela 2 (Mcgarigal e Marks, 1995). A análise do cálculo das métricas foi realizado somente para as classes de Floresta (CFL), Atividade Produtiva 
(CAP) e Vegetação Secundária (CVS). Devido os dados gerados pelo TerraClass não definirem o tipo de uso do solo sobre as áreas de Não Floresta
(CNF), a análise desta classe ficaria comprometida e, portanto, não foram realizadas.

Tabela 2. Formulas das métricas individuais ${ }^{1}$.

\begin{tabular}{|c|c|c|c|}
\hline Métrica & Formula & Descrição & Resultado \\
\hline $\begin{array}{c}\text { Percentagem da } \\
\text { paisagem } \\
\text { correspondente a cada } \\
\text { classe }(\boldsymbol{P L A N D}-\mathbf{\%})\end{array}$ & $\boldsymbol{P L A N D}=p_{i}=\frac{\sum_{j=1}^{n} a_{i j}}{A}(100)$ & $\begin{array}{c}\mathrm{j}=1, \ldots, \mathrm{n} \text { manchas; } a_{i j}=\text { área }\left(\mathrm{m}^{2}\right) \\
\text { da mancha } \mathrm{ij} ; \mathrm{A}=\text { área total da } \\
\text { paisagem }\left(\mathrm{m}^{2}\right)\end{array}$ & $\begin{array}{l}\text { Relação da área da classe em questão } \\
\text { e a área total da paisagem }\end{array}$ \\
\hline $\begin{array}{l}\text { Índice de maior mancha } \\
\text { (LPI - \%) }\end{array}$ & $\boldsymbol{L P I}=\frac{\max _{j=1}^{n}\left(a_{i j}\right)}{A}(100)$ & $\begin{array}{c}\mathrm{j}=1, \ldots, \mathrm{n} \text { manchas; } a_{i j}=\text { área }\left(\mathrm{m}^{2}\right) \\
\text { da mancha ij; } \mathrm{A}=\text { área total da } \\
\text { paisagem }\left(\mathrm{m}^{2}\right)\end{array}$ & $\begin{array}{c}\text { É a percentagem da paisagem } \\
\text { ocupada pela área da maior mancha } \\
\text { da classe }\end{array}$ \\
\hline $\begin{array}{l}\text { Número de manchas } \\
\text { (NP) }\end{array}$ & $\boldsymbol{N P}=n_{i}$ & $n_{i}$ é número de manchas da classe i. & Contagem de manchas por classe \\
\hline $\begin{array}{l}\text { Tamanho médio da } \\
\text { mancha (AREA_MN - } \\
\left.\mathbf{m}^{2} / \mathbf{h a}\right)\end{array}$ & $\boldsymbol{A R E A} \boldsymbol{M} \boldsymbol{M}=\frac{\sum_{j=1}^{n} a_{i j}}{n_{i}}\left(\frac{1}{10000}\right)$ & $\begin{array}{c}\mathrm{j}=1, \ldots, \mathrm{n} \text { manchas; } a_{i j}=\text { área }\left(\mathrm{m}^{2}\right) \\
\text { da mancha ij; } \mathrm{ni}=\text { número de } \\
\text { manchas da classe } \mathrm{i} \text { ou o número de } \\
\text { todas as manchas da paisagem. }\end{array}$ & $\begin{array}{c}\text { é obtido em hectare e corresponde a } \\
\text { média dos tamanhos das manchas de } \\
\text { uma classe ou de todas as manchas da } \\
\text { paisagem. }\end{array}$ \\
\hline $\begin{array}{l}\text { Densidade de bordas } \\
\quad(\mathbf{E D}-\mathbf{m} / \mathbf{h a})\end{array}$ & $\boldsymbol{E} \boldsymbol{D}=\frac{\sum_{k=1}^{m} e_{i j}}{A}(10000)$ & $\begin{array}{c}e_{i j}=\text { tamanho total da borda entre } \\
\text { tipos de manchas i e } \mathrm{k} ; \mathrm{A}=\text { área total } \\
\text { da paisagem }\left(\mathrm{m}^{2}\right) .\end{array}$ & $\begin{array}{l}\text { Razão entre o comprimento das } \\
\text { bordas em metro e a área das } \\
\text { classes/paisagem em m² }\end{array}$ \\
\hline $\begin{array}{c}\text { Índice de forma da } \\
\text { paisagem (LSI) }\end{array}$ & $\boldsymbol{L S I}=\frac{0.25 \sum_{k=1}^{m} e_{i j}}{\sqrt{A}}$ & $\begin{array}{c}e_{i j}=\text { tamanho total da borda entre } \\
\text { tipos de manchas i e } \mathrm{k} ; \mathrm{A}=\text { área total } \\
\text { da paisagem }\left(\mathrm{m}^{2}\right) .\end{array}$ & $\begin{array}{l}\text { LSI mais próximo de } 1 \text { mais circular } \\
\text { é a área, e quanto mais afastado mais } \\
\text { recortada é a forma da mancha } \\
\text { (Mcgarigal et al., 1995). O principal } \\
\text { aspecto da forma é a relação com o } \\
\text { efeito de borda (Volatão, 1998). }\end{array}$ \\
\hline $\begin{array}{l}\text { Taxa de crescimento } \\
\text { anual (TCA-\%) }\end{array}$ & $\boldsymbol{T C A}=\left((f / i)^{1 / a}-1\right) * 100$ & $\begin{array}{l}\text { f é o valor final, i o valor inicial e a o } \\
\text { número de anos. }\end{array}$ & $\begin{array}{c}\text { Determina a variação da métrica ao } \\
\text { longo do período. }\end{array}$ \\
\hline
\end{tabular}

Fonte: Elaborada e estruturada pelo autor, 2018.

À análise da estrutura fundiária, foram utilizados dos dados relativos aos imóveis certificados pelo INCRA ${ }^{2}$ e Programa Terra Legais do governo federal, e ainda, os dados de unidades de conservação do $\mathrm{MMA}^{3}$ e de terra indígenas da $\mathrm{FUNAI}^{4}$. O grau de concentração de terra foi avaliado considerando os percentuais de cada estrato de propriedades rurais por classe conforme definido no Estatuto da Terra (BRASIL, 1964), onde as propriedades são caracterizadas em quatro classes: minifúndio, pequena, média e grande propriedades ou latifúndios a partir do módulo fiscal (BRASIL, 2013). As propriedades com menos de 1 módulo fiscal é classificada como minifúndio, entre 1 e 4 módulos fiscais é pequena, entre 5 e 15 módulos fiscais média e aquelas que possuem mais de 15 módulos fiscais são consideradas grandes propriedades ou latifúndios. $\mathrm{O}$ valor do módulo fiscal utilizado às áreas das propriedades da bacia do rio Xingu foi o mesmo determinado pelo INCRA, os quais variam entre as regiões, para a bacia do Xingu (estado do Pará e Mato Grosso) foi considerado o valor de 80 ha, e com base nesse valor os dados foram classificados por tamanho de área conforme estabelecidos na Tabela 3.

Tabela 3. Classificação dos imóveis rural por tamanho de área.

\begin{tabular}{ll}
\hline Classe & Tamanho de Área (ha) \\
\hline Minifúndio & Menor ou igual a 80 \\
Pequena & Maior que 80 e menos 320 \\
Média & Maior que 320 a 1.200 \\
Grande ou & Maio de 1.200 \\
Latifúndio & \\
\hline
\end{tabular}

Fonte: INCRA, 2018.

\section{Resultado e discussão}

Estrutura Fundiária - a situação da estrutura fundiária na bacia do Xingu é bastante complexa em termo de distribuição e ocupação da sua área territorial. Conforme Tabela 4,

\footnotetext{
${ }^{1}$ As fórmulas e enquadramento conceitual são extraídas e adaptadas de Mcgarigal, Kevin; Marks, Barbara (1995), Farina, Almo (2000) e Forman, R.T. (1999).

2 Instituto de Colonização e Reforma Agrária

${ }^{3}$ Ministério do Meio Ambiente

${ }^{4}$ Fundação Nacional do Índio
}

Santos, F.A.A.; Rocha, E.J.P.; Santos, J.S. 
aproximadamente $79 \%$ da área da bacia, cerca de $449.222 \mathrm{~km}^{2}$, são terras de destinação pública as quais já têm aplicação específica definida por lei, como as Terras Indígenas $(39,5 \%)$ e as Unidades de Conservação $(12,7 \%)$. Contudo, ainda existe uma quantidade expressiva de terras arrecadas pela União ou pelos estados sob a condição de devolutas5 (4,9\%), e outras já arrecadadas que serão destinadas à privatização por intermédio do Programa Terra Legal do governo Federal.

Sob o domínio legalizado da iniciativa privada estão aproximadamente $84.521,98 \mathrm{~km}^{2}$, que corresponde a $18,8 \%$ da área da bacia. Deste total, apenas $3,7 \%\left(16.427,63 \mathrm{~km}^{2}\right)$ são áreas destinadas aos assentamentos de reforma agrária e de colonização, $15,2 \%$ são terras de imóveis privados já certificados pelo INCRA que corresponde $69.247,08 \mathrm{~km}^{2}$, e o restante, cerca de 20,6\% (92.386,35 km²) são terras publicas federais ou estaduais ainda não destinada para nenhum uso.

Tabela 4. Estrutura fundiária da bacia do rio Xingu.

\begin{tabular}{lrr}
\hline \multicolumn{1}{c}{ Área Especial Protegida } & \multicolumn{1}{c}{$\begin{array}{c}\text { Área } \\
\left(\mathrm{km}^{2}\right)\end{array}$} & \multicolumn{1}{c}{$\%$} \\
\hline Terras Indígenas & $177.247,29$ & 39,5 \\
UC Proteção Integral Federal & $13.775,23$ & 3,1 \\
UC Proteção Integral Estadual & $2.022,08$ & 0,5 \\
UC Uso Sustentável Federal & $19.696,81$ & 4,4 \\
UC Uso Sustentável Estadual & $21.230,66$ & 4,7 \\
Terra Militar & 761,00 & 0,2 \\
\hline Total & $\mathbf{2 3 3 . 9 7 2 , 0 7}$ & $\mathbf{5 2 , 1}$ \\
\hline \multicolumn{1}{c}{ Demais áreas } & Total & \% \\
\hline
\end{tabular}

\footnotetext{
${ }^{5}$ Terras devolutas são terras públicas sem destinação pelo Poder Público e que em nenhum momento
} Santos, F.A.A.; Rocha, E.J.P.; Santos, J.S.
Assentamento de reforma agrária e área de colonização $16.427,63$ 3,6 Imóvel privado (certificado) $68.247,08 \quad 15,2$ Terra pública federal não destinada $33.572,60$

Terra pública estadual não destinada $36.829,80$

Terras devoluta e/ou com

$21.983,95 \quad 4,9$

situação fundiária indefinida $21.983,95$
Fonte: INCRA/2018, MMA/2108 e FUNAI/2018.

A distribuição geográfica das terras indígenas e unidades de conservação grande parte estão localizadas no estado do Pará, no médio e baixo Xingu. No estado do Mato Grosso, no alto Xingu, encontra-se a continuidade da terra indígena existentes no território paraense, as quais margeiam ambos os lados do rio Xingu. Comparativamente com o estado do Pará onde as unidades de conservação têm tamanho expressivo, no Mato Grosso as mesmas apresentam áreas de tamanho bastante reduzido (Figura 2-a).

Na Figura 2-b, observa-se que os imóveis privados certificados já ocupam praticamente o restante da área da bacia, passando a exercer uma pressão sobre as terras indígenas e unidades de conservação, onde também, já é possível observar algumas dessas áreas de ocupações privadas no interior dos limites das unidades de conservação.

Nas sub-bacias do rio Curuá (médio Xingu) e do rio Ronuro (alto Xingu) é registrado o maior nível de ocupação privada certificada, $32 \%$ e $53,4 \%$ respectivamente, enquanto que, a sub-bacia do rio Fresco registra apenas uma taxa de ocupação de $3 \%$.

integraram o patrimônio de um particular, ainda que estejam irregularmente sob sua posse (INCRA, 2018). 

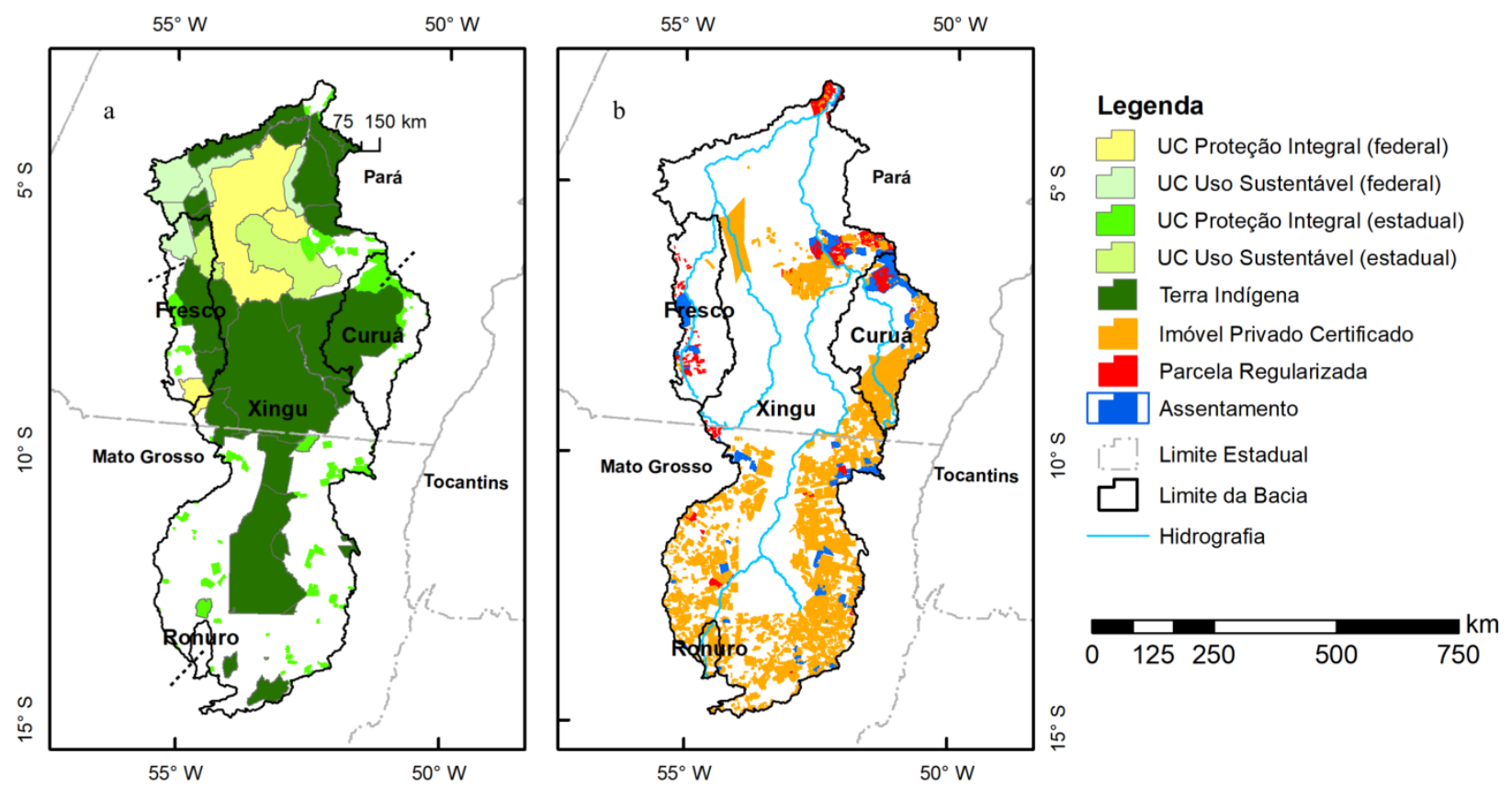

Figura 2. (a) Estrutura fundiária da bacia do rio Xingu, terras públicas destinadas (Fonte: MMA, 2018), e (b) de imóveis privados e assentamentos certificados pelo INCRA (Fonte: INCRA, 2018).

A estrutura fundiária é um importante fator relacionado à atividade produtiva, bem como à sua distribuição. Os resultados das análises sobre as terras privadas agrupadas por tamanho de área, apresentados na Tabela 5, mostram que na bacia do rio Xingu $19,31 \%$ dos imóveis apresenta tamanho de área acima 1.000 ha, os quais concentram aproximadamente $88,79 \%$ das áreas dos imóveis certificados. Observa-se também, que as 1.656 imóveis totalizam uma área de 8.123.097,38 ha, sendo que, a soma dos demais imóveis com área inferior 1.000 ha (6.928), totalizam apenas 1.025.113,76 ha.
Quando se analisa a estrutura fundiária das três sub-bacias, observa-se que o mesmo padrão se repete nas sub-bacias do Curuá e Runoro, porém, com índices ainda superiores para os imóveis com área acima 1.000 ha, 98,65\% e 90,63\%, respectivamente. Já na sub-bacia do rio Fresco a estrutura fundiária apresenta comportamento diferente em relação à concentração do tamanho dos imóveis, 55,08\% são de áreas de até 1.000 ha, e a faixa predominante é de áreas entre 100 a 800 ha $(35,72 \%)$.

Tabela 5. Distribuição dos imóveis certificados por tamanho de área.

\begin{tabular}{lcccccccc} 
& \multicolumn{2}{c}{ Bacia } & \multicolumn{1}{c}{ Sub-bacia } \\
\multicolumn{1}{c}{ Área } & \multicolumn{2}{c}{ Rio Xingu } & \multicolumn{2}{c}{ Rio Fresco } & \multicolumn{2}{c}{ Rio Curuá } & \multicolumn{2}{c}{ Rio Ronuro } \\
& \% de & $\%$ de & \multicolumn{2}{c}{$\%$ de } & $\%$ de & \% de & $\%$ de & \multicolumn{2}{c}{$\%$ de } & $\%$ de \\
& Imóvel & Área & Imóvel & Área & Imóvel & Área & Imóvel & Área \\
\hline$<=10$ & 4,06 & 0,01 & 3,03 & 0,04 & 2,40 & 0 & 0 & 0 \\
$10-25$ & 8,29 & 0,04 & 1,01 & 0,04 & 3,90 & 0,02 & 0 & 0 \\
$25-50$ & 6,99 & 0,09 & 1,01 & 0,08 & 14,47 & 0,17 & 0 & 0 \\
$50-100$ & 20,48 & 0,51 & 4,55 & 0,61 & 16,94 & 0,36 & 0 & 0 \\
$100-200$ & 10,23 & 0,43 & 10,61 & 2,80 & 11,09 & 0,47 & 0 & 0 \\
$200-500$ & 8,84 & 0,98 & 43,94 & 28,04 & 9,07 & 0,88 & 3,77 & 0,10 \\
$500-1000$ & 7,76 & 1,85 & 19,70 & 26,07 & 6,22 & 1,37 & 1,89 & 0,10 \\
$1.000-10.000$ & 27,23 & 29,58 & 16,16 & 42,32 & 27,74 & 31,46 & 50,94 & 10,47 \\
$>10.000$ & 6,11 & 66,50 & 0,00 & 0,00 & 8,17 & 65,26 & 43,40 & 89,33 \\
\hline
\end{tabular}

Fonte: Terra Legal (2018). 
Com base nos dados da Tabela 6, observase que $31,8 \%$ dos imóveis inseridos na bacia do rio Xingu são de minifúndios e $22,9 \%$ de pequenas propriedades, porém, concentram respectivamente, apenas $0,4 \%$ e $1,1 \%$, do total de área dos imóveis certificados. Por outro lado, as médias propriedades e os latifúndios representam respectivamente $14,8 \%$ e $30,5 \%$ do número de imóveis, contudo concentram $98,6 \%$ do total das áreas dos imóveis certificados.

Tabela 6. Classificação dos imóveis rural por tamanho de área.

\begin{tabular}{|c|c|c|c|c|c|c|c|c|}
\hline \multirow[b]{2}{*}{ Classe de Área Total } & \multicolumn{2}{|c|}{ Rio Xingu } & \multicolumn{2}{|c|}{ Rio Fresco } & \multicolumn{2}{|c|}{ Rio Curuá } & \multicolumn{2}{|c|}{ Rio Ronuro } \\
\hline & $\begin{array}{l}\% \text { de } \\
\text { Imóvel }\end{array}$ & $\begin{array}{l}\% \text { de } \\
\text { Área }\end{array}$ & $\begin{array}{l}\% \text { de } \\
\text { Imóvel }\end{array}$ & $\begin{array}{l}\% \text { de } \\
\text { Área }\end{array}$ & $\begin{array}{c}\% \text { de } \\
\text { Imóvel }\end{array}$ & $\begin{array}{l}\% \text { de } \\
\text { Área }\end{array}$ & $\begin{array}{l}\% \text { de } \\
\text { Imóvel }\end{array}$ & $\begin{array}{l}\% \text { de } \\
\text { Área }\end{array}$ \\
\hline Minifúndio & 31,8 & 0,4 & 8,1 & 0,5 & 32,6 & 0,4 & 0 & 0 \\
\hline Pequena Propriedade & 22,9 & 1,1 & 34,3 & 14,1 & 21,9 & 1,1 & 1,9 & 0 \\
\hline Média Propriedade & 14,8 & 3,5 & 55,1 & 69,9 & 11,5 & 2,5 & 7,5 & 0,5 \\
\hline Latifúndio & 30,5 & 95,1 & 2,5 & 15,5 & 34,0 & 96,1 & 90,6 & 99,5 \\
\hline
\end{tabular}

Fontes: Terra Legal (2018).

Os dados da sub-bacias do rio Curuá (Tabela 6), mostra que o resultado obtido é semelhante ao da bacia do rio Xingu, onde o maior número de imóveis é de minifúndio e pequena propriedade que totalizam 54,5\%, porém, concentram apenas $1,5 \%$ do total de áreas dos imóveis certificados. Os latifúndios correspondem a $34 \%$ do número total de imóveis certificados e concentram a maior quantidade de área, $89,4 \%$ do total.

$\mathrm{Na}$ sub-bacia do rio Fresco o padrão fundiário já é diferente das demais áreas. A maioria dos imóveis está concentrada nas classes de pequena e média propriedade $(94,4 \%)$, e concentram $84 \%$ do total de áreas dos imóveis certificados. Os minifúndio e latifúndio correspondem a $0,04 \%$ e $15,48 \%$, respectivamente, do número de imóveis certificados e acumulam uma área de $16 \%$.

A sub-bacia do rio Ronuro apresenta um padrão fundiário composto basicamente pelas classes de pequena, média e grande propriedade (latifúndio). Os latifúndios predominam com 90,6\% do número de imóveis certificados e concentram $99,5 \%$ da área total certificada. O restante, $9,4 \%$ é imóvel de pequena e média propriedade que totalizam apenas $0,53 \%$ do total de área.

Com base nos resultados obtidos, pode-se afirmar que as áreas especialmente protegidas (unidades de conservação, terras indígenas e áreas militar) que compõe a estrutura fundiária da bacia do rio Xingu, exercem papel preponderante de contenção do avanço do desmatamento sobre as áreas de vegetação primária, principalmente, sobre as áreas de florestas.

Na Figura 2 é possível observar que as propriedades privadas se concentram ao entorno das áreas especialmente protegidas, formando um cinturão de ocupações, onde mais de $95 \%$ das terras certificadas pelo governo federal na bacia do rio
Xingu está concentrado em propriedades enquadradas como grande latifúndio. Esse tipo de propriedade, geralmente tem como atividade produtiva o agronegócio, que se caracteriza pela produção em grandes áreas. Desta forma, este resultado conforme os estudos realizados por Broadbent et al. (2008), a exploração de extensas áreas têm fragmentado a Amazônia e vem criando grandes áreas de floresta susceptíveis aos efeitos de bordas.

Análise das Métricas - a avaliação da evolução da fragmentação da cobertura original foi realizada a partir de comparação das métricas geradas com base nos mapas de uso do solo para os anos de 2004, 2008, 2010, 2012 e 2014. Foram estudadas as métricas para as categorias de classe e mancha, de modo que as análises e interpretações ocorreram de forma individual.

PLAND da Bacia do Rio Xingu - Os dados mostra que no período de 2004 a 2014 ocorreu uma redução da CFL, contudo, a taxa de crescimento anual (TCA) indica uma tendência de redução destas perdas. O período mais crítico foi o de 2004 a 2008, com uma TCA de $-0,5 \%$ (Tabela 7 e Figura 3). Observa-se que em 2014 o uso do solo predominante na paisagem da bacia hidrográfica do rio Xingu ainda era a CFL com $67,79 \%$, seguida da CAP com $15,49 \%$ e da classe de vegetação secundária (CVS) 2,94\%.

$\mathrm{Na}$ Figura 3 considerando a TCA da PLAND à CVS, observa-se que o comportamento registrou um pico de redução elevado de $-21,8 \%$ no período de 2008 a 2010 e outro de 33,2\% em 2010 a 2012, os quais são influenciados diretamente pelo comportamento da CAP. A TCA da PLAND da CAP mostra que o auge do crescimento da atividade produtiva na bacia ocorreu entre os anos de 2004 a 2008.

Com base nos dados obtidos, constata-se que a bacia do rio Xingu já perdeu 
aproximadamente $32 \%$ da sua cobertura florestal, atualmente, a maior parte da vegetação primitiva existente está localizada nas áreas especialmente protegidas que compõe a estrutura fundiária dessa bacia.

Tabela 7. Comportamento da PLAND ao nível da classe de uso do solo da bacia do rio Xingu.

\begin{tabular}{ccccccc}
\hline \multirow{2}{*}{ Período } & \multicolumn{6}{c}{ PLAND - Bacia do Rio Xingu } \\
& $\begin{array}{c}\text { CFL } \\
(\%)\end{array}$ & $\begin{array}{c}\text { TCA } \\
(\%)\end{array}$ & $\begin{array}{l}\text { CAP } \\
(\%)\end{array}$ & \multicolumn{1}{c}{ TCA } \\
$(\%)$ & $\begin{array}{l}\text { CVS } \\
(\%)\end{array}$ & $\begin{array}{c}\text { TCA } \\
(\%)\end{array}$ \\
\hline 2004 & 70.3 & - & 13.5 & - & 2.4 & \multicolumn{1}{l}{-} \\
$2004-08$ & 68.8 & -0.5 & 14.7 & 2.2 & 2.7 & 2.7 \\
$2008-10$ & 68.5 & -0.3 & 16.1 & 4.7 & 1.6 & -21.8 \\
$2010-12$ & 68.1 & -0.2 & 15.2 & -3.0 & 2.9 & 33.2 \\
$2012-14$ & 67.8 & -0.3 & 15.5 & 1.0 & 2.9 & 0.8
\end{tabular}

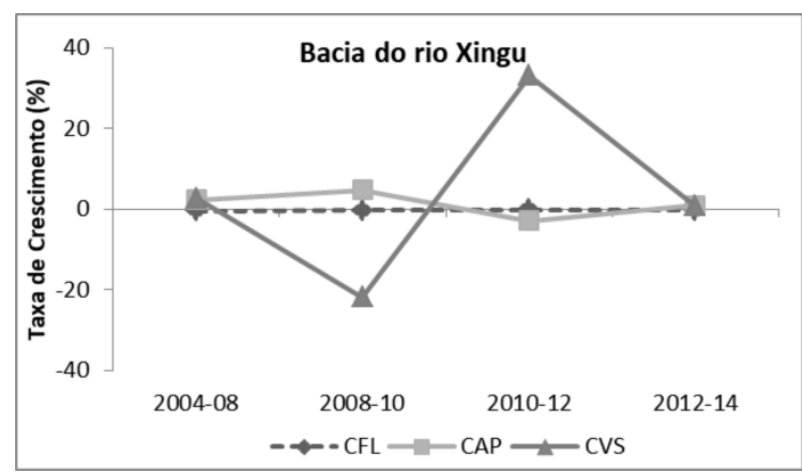

Figura 3. Comportamento da TCA da PLAND para a bacia do rio Xingu. Fonte: Autor, 2018.

PLAND Sub-bacia do Rio Fresco - Os dados mostram que diferentemente do resultado da bacia do rio Xingu, o período de maior redução da CFL se deu entre os anos de 2012 a 2014 para uma TCA da PLAND de -0,8\% (Tabela 8). Contudo, em 2014 ainda existia 83,8\% de sua paisagem preservada por floresta, índice este maior que o da bacia do rio Xingu. A TCA da PLAND à CAP apresentou dois picos de alta, um em 2004 a 2008 de $10,8 \%$ e o outro ainda maior em 2012 a 2014 de $12,8 \%$. Na Figura 4 é observar que as variações positivas da CAP então sempre influenciando a redução da CFL e, na maioria das vezes, também a CVS.

Tabela 8. Comportamento da PLAND ao nível da classe de uso do solo da sub-bacia do rio Fresco.

\begin{tabular}{|c|c|c|c|c|c|c|}
\hline \multirow[b]{2}{*}{ Período } & \multicolumn{6}{|c|}{ PLAND - Sub-bacia do Rio Fresco } \\
\hline & $\begin{array}{l}\mathrm{CFL} \\
(\%)\end{array}$ & $\begin{array}{l}\text { TCA } \\
(\%) \\
\end{array}$ & $\begin{array}{l}\text { CAP } \\
(\%)\end{array}$ & $\begin{array}{c}\text { TCA } \\
(\%) \\
\end{array}$ & $\begin{array}{l}\text { CVS } \\
(\%)\end{array}$ & $\begin{array}{l}\text { TCA } \\
(\%)\end{array}$ \\
\hline 2004 & 89.7 & - & 3.9 & - & 0.6 & - \\
\hline 2004-08 & 87.2 & -0.7 & 5.9 & 10.8 & 1.1 & 15.2 \\
\hline 2008-10 & 86.1 & -0.7 & 7.0 & 8.4 & 1.2 & 5.7 \\
\hline 2010-12 & 85.2 & -0.5 & 7.2 & 1.5 & 1.9 & 24.1 \\
\hline
\end{tabular}

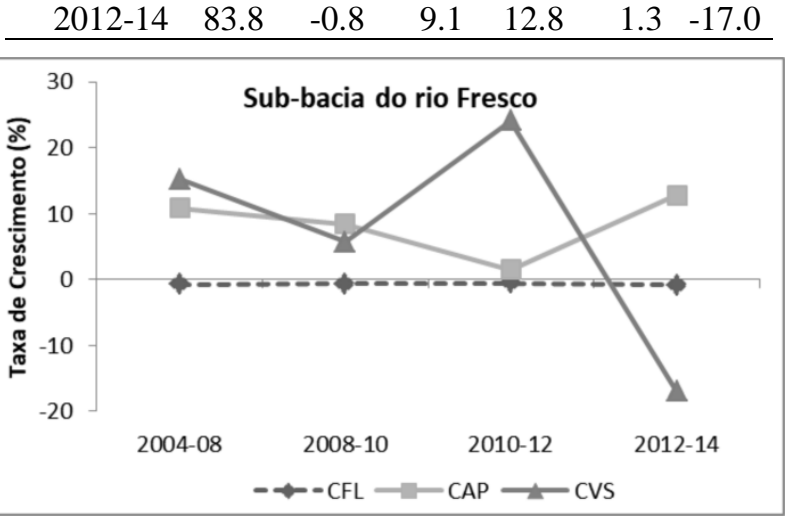

Figura 4. Comportamento da TCA da PLAND para a sub-bacia do rio Fresco. Fonte: Autor, 2018.

PLAND Sub-bacia do Rio Curuá - Nesta sub-bacia os dados da PLAND mostram que existe um grande comprometimento da CFL (Tabela 9), no período de 10 anos, é computada uma perda de aproximadamente $5 \%$ da cobertura florestal. No período mais crítico a TCA foi de $-1,8 \%$, ocasionada pelo aumento da TCA da PLAND da CAP (3\%). Na Figura 5 observa-se que no período 2012 a 2014 a TCA da PLAND da CVS registra um aumento significativo de $14 \%$, fato ocasionado pela redução da TCA de $-1,8 \%$ observada para este mesmo período à PLAND da CAP.

Tabela 9. Comportamento da PLAND ao nível da classe de uso do solo da sub-bacia do rio Curuá.

\begin{tabular}{ccccccc}
\hline \multirow{2}{*}{ Período } & \multicolumn{6}{c}{ PLAND - Sub-bacia do rio Curuá } \\
& $\begin{array}{c}\text { CFL } \\
(\%)\end{array}$ & $\begin{array}{c}\text { TCA } \\
(\%)\end{array}$ & $\begin{array}{c}\text { CAP } \\
(\%)\end{array}$ & $\begin{array}{c}\text { TCA } \\
(\%)\end{array}$ & $\begin{array}{c}\text { CVS } \\
(\%)\end{array}$ & $\begin{array}{c}\text { TCA } \\
(\%)\end{array}$ \\
\hline 2004 & 58.8 & - & 25.7 & - & 3.3 & - \\
$2004-08$ & 54.7 & -1.8 & 28.9 & 3.0 & 4.2 & 6.5 \\
$2008-10$ & 54.3 & -0.3 & 29.1 & 0.3 & 4.4 & 1.8 \\
$2010-12$ & 54.0 & -0.3 & 29.6 & 0.8 & 4.2 & -1.5 \\
$2012-14$ & 53.8 & -0.2 & 28.5 & -1.8 & 5.5 & 14.0 \\
\hline
\end{tabular}

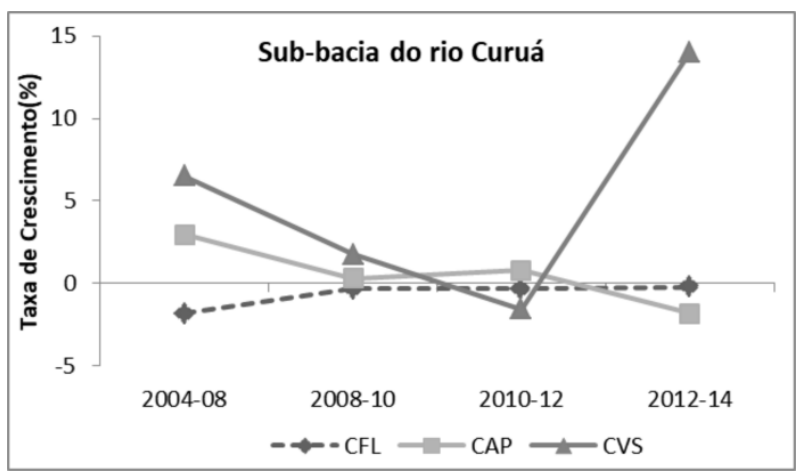

Figura 5. Comportamento da TCA da PLAND para a sub-bacia do rio Curuá.

PLAND da Sub-bacia do Rio Ronuro mostra que em 2014 a CNF ocupava $68,7 \%$ da sua área segundo a classificação do TerraClass (Tabela 10). Seguindo o que ocorreu nas demais sub-bacias, 
a CFL teve sua maior perda entre os anos de 2004 a 2008, a uma TCA de $-3,5 \%$, está supressão da florestal foi ocasionada também, pela expansão da CAP. Contudo, conforme mostra a Figura 6, entre 2008 a 2010 ocorre uma retração da atividade produtiva que contribuiu para a redução da TCA em $-0,2 \%$. No ultimo período (2012-2014), quando a CAP volta a se expandir, observa-se novamente a influência sobre a CVS e CFL.

Tabela 10. Comportamento da PLAND ao nível da classe de uso do solo da sub-bacia do rio Ronuro.

\begin{tabular}{rcccccc}
\hline \multirow{6}{*}{ Período } & $\begin{array}{c}\text { CFL } \\
(\%)\end{array}$ & $\begin{array}{c}\text { TCA } \\
(\%)\end{array}$ & $\begin{array}{c}\text { CAP } \\
(\%)\end{array}$ & $\begin{array}{c}\text { TCA } \\
(\%)\end{array}$ & $\begin{array}{c}\text { CVS } \\
(\%)\end{array}$ & $\begin{array}{c}\text { TCA } \\
(\%)\end{array}$ \\
\hline 2004 & 18.2 & - & 11.7 & - & 1.3 & - \\
$2004-08$ & 15.8 & -3.5 & 14.6 & 5.8 & 0.9 & -10.6 \\
$2008-10$ & 15.7 & -0.2 & 14.8 & 0.7 & 0.7 & -9.4 \\
$2010-12$ & 15.6 & -0.4 & 14.0 & -2.9 & 1.7 & 54.6 \\
$2012-14$ & 15.5 & -0.4 & 14.7 & 2.5 & 1.1 & -19.3 \\
\hline
\end{tabular}

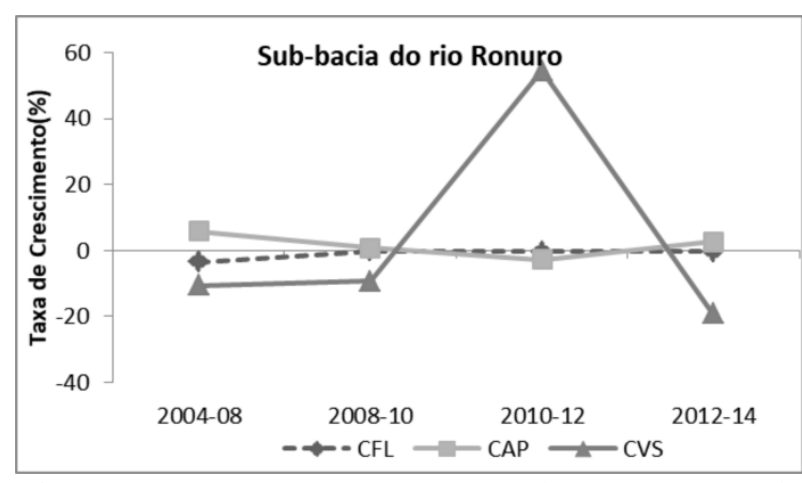

Figura 6. Comportamento da taxa de crescimento anual (TCA) referente à PLAND para as áreas de estudo.

O comportamento observado da PLAND à CFL e CAP na bacia do rio Xingu e sub-bacias dos rios Fresco, Curuá e Ronuro estão coerentes aos resultados dos dados PPCDAM (Figura 7), que aponta para o decrescimento da taxa anual de desmatamento na Amazônia Legal a partir de 2004 (BNDES, 2012). Quanto às oscilações da CAP ao longo do período estudados, essas são explicadas com base nos dados econômicos do Brasil, através das alternâncias entre crescimento e desacelerações, muitas vezes abruptas como mostra os resultados das análises de Paula (2017) (Figura 8).

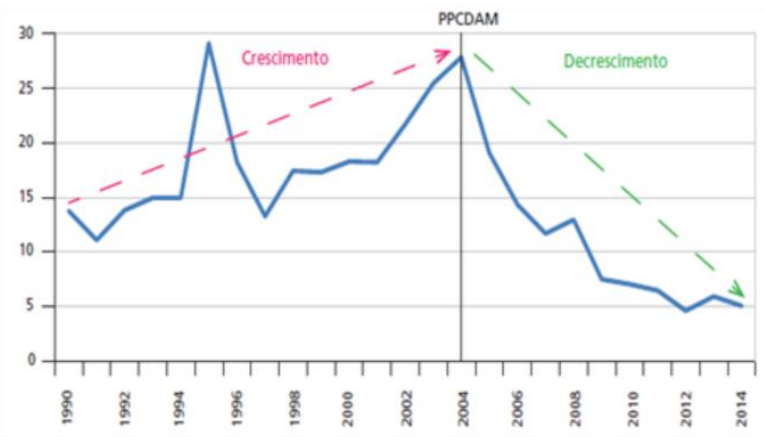

Figura 7. Taxa anual do desmatamento na Amazônia Legal (1990-2014) (escala em 1 mil $\mathrm{Km}^{2}$ ). Fonte- PRODES/INPE.

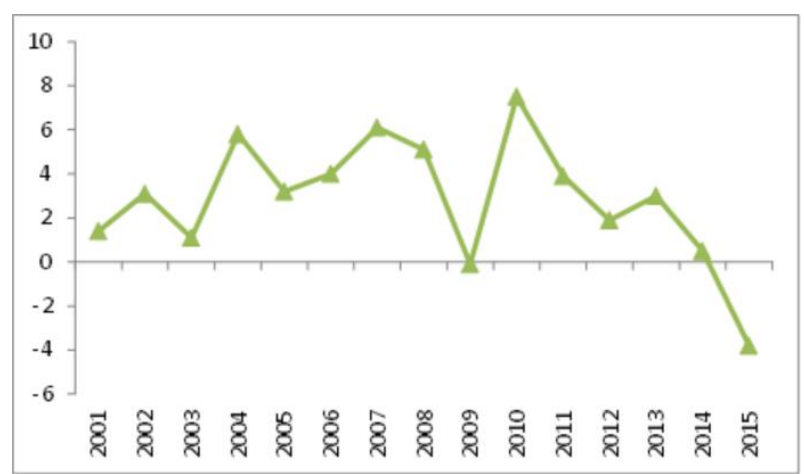

Figura 8. Crescimento do PIB real (\% a.a.). Fonte-IBGE.

LPI da Bacia do Rio Xingu - Em 2004, uma única mancha ocupava aproximadamente $46,8 \%$ da paisagem e, em 2014, esta mesma mancha teve seu tamanho reduzido em torno de $1,6 \%$, o que corresponde a uma área de aproximadamente $6.965,6 \mathrm{~km}^{2}$ (Tabela 11). As oscilações observadas à CAP a partir da TCA da LPI mostra que seu comportamento influenciou não só as variações da CFL como também a CVS. Na Figura 9 é possível verificar que entre 2012 a 2014 ocorreu uma grande dedução da maior mancha da CAP $(-17,3 \%)$, fato este que afetou diretamente a TCA da LPI da CVS, que atingiu no último período um crescimento de $26,3 \%$.

Tabela 11. Comportamento da LPI ao nível da classe de uso do solo da bacia do rio Xingu.

\begin{tabular}{rcccccc}
\hline & \multicolumn{6}{c}{ LPI - Bacia do rio Xingu } \\
Período & $\begin{array}{c}\text { CFL } \\
(\%)\end{array}$ & $\begin{array}{c}\text { TCA } \\
(\%)\end{array}$ & $\begin{array}{c}\text { CAP } \\
(\%)\end{array}$ & $\begin{array}{c}\text { TCA } \\
(\%)\end{array}$ & $\begin{array}{c}\text { CVS } \\
(\%)\end{array}$ & $\begin{array}{c}\text { TCA } \\
(\%)\end{array}$ \\
\hline 2004 & 46.8 & - & 2.2 & - & 0.01 & - \\
$2004-08$ & 46.1 & -0.4 & 2.6 & 4.5 & 0.01 & 0.0 \\
$2008-10$ & 45.8 & -0.3 & 2.7 & 1.0 & 0.01 & 0.0 \\
$2010-12$ & 45.6 & -0.2 & 2.8 & 2.6 & 0.02 & 24.0 \\
$2012-14$ & 45.2 & -0.4 & 1.9 & -17.3 & 0.03 & 26.3 \\
\hline
\end{tabular}




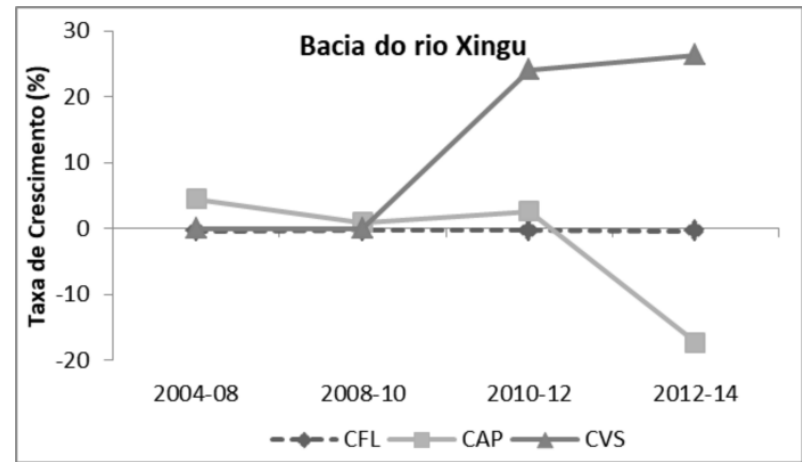

Figura 9. Comportamento da TCA da LPI para a bacia do rio Xingu.

LPI da Sub-bacia do Rio Fresco - O comportamento da LPI apresentou a mesma tendência da bacia como um todo, contudo, as variações foram mais acentuadas (Tabela 12). Entre 2004 e 2008, a CFL teve uma redução de $6,6 \%$ na área da sua maior mancha, o que equivale a aproximadamente $2.345,7 \mathrm{~km}^{2}$. A CAP apresentou dois períodos consecutivos em que a TCA do LPI registrou valores positivo (2004 a 2008 e 2008 a 2010), ou seja, o tamanho da sua maior mancha aumentou. No entanto, entre 2010 a 2012 ocorreu uma redução da TCA de $-33,3 \%$ da LPI, voltando a crescer no período seguinte em 27,2\%. Na Figura 10 é possível verificar que as variações da CAP influenciaram diretamente a CFL e principalmente CVS. O aumento da maior mancha da CSV é ocasionado quase sempre pela desaceleração da atividade produtiva, ou seja, no abandono de áreas por um longo período. as oscilações observadas na CAP podem ter sido influenciada pela característica fundiária das propriedades dessa sub-bacia, onde os imóveis certificados são na sua maioria de pequenas e médias propriedades, as quais, são mais suscetíveis ao comportamento da economia.

Tabela 12. Comportamento da LPI ao nível da classe de uso do solo da sub-bacia do rio Fresco.

\begin{tabular}{rcccccc}
\hline & \multicolumn{6}{c}{ LPI - Sub-bacia do rio Fresco } \\
Período & $\begin{array}{c}\text { CFL } \\
\end{array}$ & $\begin{array}{c}\text { TCA } \\
(\%)\end{array}$ & $\begin{array}{c}\text { CAP } \\
(\%)\end{array}$ & $\begin{array}{c}\text { TCA } \\
(\%)\end{array}$ & $\begin{array}{c}\text { CVS } \\
(\%)\end{array}$ & $\begin{array}{c}\text { TCA } \\
(\%)\end{array}$ \\
\hline 2004 & 87.2 & - & 0.5 & - & 0.01 & - \\
$2004-08$ & 84.5 & -0.8 & 1.3 & 24.4 & 0.01 & 4.3 \\
$2008-10$ & 83.2 & -0.7 & 2.1 & 28.1 & 0.02 & 26.0 \\
$2010-12$ & 82.3 & -0.6 & 0.9 & -33.3 & 0.04 & 31.4 \\
$2012-14$ & 80.6 & -1.0 & 1.5 & 27.2 & 0.04 & -2.1 \\
\hline
\end{tabular}

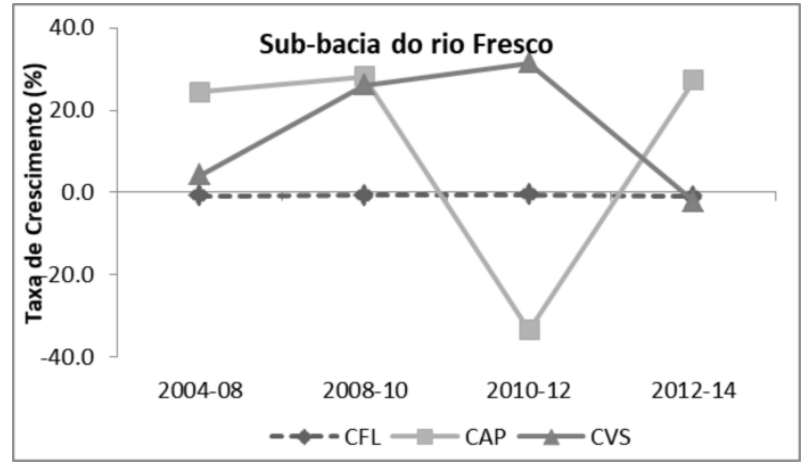

Figura 10. Comportamento da TCA da LPI para a sub-bacia do rio Fresco.

LPI da Sub-bacia do Rio Curuá - A LPI da $\boldsymbol{C F L}$ desta sub-bacia foi a que sofreu maior perda ao $\log$ o de 10 anos. Sua maior mancha reduziu em $7,4 \%$, equivalente a uma área de aproximadamente $3.160,3 \mathrm{~km}^{2}$ de floresta (Tabela 13). As perdas ocorreram principalmente no período de 2004 a 2008, quando foi registrada uma redução na TCA de $-3,5 \%$ na LPI da $\boldsymbol{C F L}$. A CAP e CVS tiveram comportamentos semelhantes até o período de 2010 a 2012, no ano seguinte, enquanto a TCA da CAP registra uma redução de $-4,2 \%$, a da CVS registra um aumento de 14\% (Figura 11).

Tabela 13. Comportamento da LPI ao nível da classe de uso do solo da sub-bacia do rio Curuá.

\begin{tabular}{ccccccc}
\hline \multirow{2}{*}{ Período } & \multicolumn{6}{c}{ LPI - Sub-bacia do rio Curuá } \\
& $\begin{array}{c}\text { CFL } \\
(\%)\end{array}$ & $\begin{array}{c}\text { TCA } \\
(\%)\end{array}$ & $\begin{array}{c}\text { CAP } \\
(\%)\end{array}$ & $\begin{array}{c}\text { TCA } \\
(\%)\end{array}$ & $\begin{array}{c}\text { CVS } \\
(\%)\end{array}$ & $\begin{array}{c}\text { TCA } \\
(\%)\end{array}$ \\
\hline 2004 & 51.2 & - & 17.4 & - & 3.3 & - \\
$2004-08$ & 44.4 & -3.5 & 18.3 & 1.4 & 4.2 & 6.5 \\
$2008-10$ & 44.2 & -0.2 & 18.3 & -0.1 & 4.4 & 1.8 \\
$2010-12$ & 44.0 & -0.2 & 18.6 & 0.7 & 4.2 & -1.5 \\
$2012-14$ & 43.8 & -0.2 & 17.1 & -4.2 & 5.5 & 14.0 \\
\hline
\end{tabular}

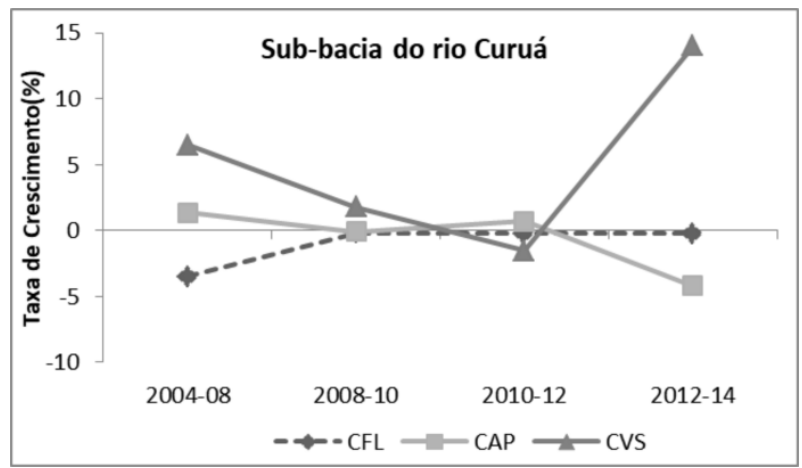

Figura 11. Comportamento da TCA da LPI para a sub-bacia do rio Curuá.

LPI Sub-bacia do Rio Curuá - A CFL apresentou redução da TCA somente para os períodos 2004-2008 (-3,7\%) e 2010-2012 (-0,6\%), nos demais períodos não ocorreram alterações significativas no valor da LPI (Tabela 11). Com 
relação à $\boldsymbol{C A P}$, o crescimento da TCA foi positivo somente para os dois primeiros períodos $(4,1 \%$ e $1,8 \%$, respectivamente), e de redução para os dois últimos (-1,5\% e -28\%, respectivamente). Em 2004, a maior mancha da CAP correspondia a uma área de $312,6 \mathrm{~km}^{2}$ e, em 2014, essa área reduziu quase pela metade, chegando a $121,0 \mathrm{~km}^{2}$. Na Figura 12 observa-se que a TCA da LPI da CVS apresentou redução no primeiro e último período $(-9,6 \%$ e $35,3 \%$, respectivamente) e aumento da sua maior mancha entre os anos de 2008 e $2012(63,1 \%$ e $38,8 \%$, respectivamente).

Tabela 14. Comportamento da LPI ao nível da classe de uso do solo da sub-bacia do rio Ronuro.

\begin{tabular}{rrrrrrrr}
\hline \multirow{2}{*}{ Período } & \multicolumn{6}{c}{ LPI - Sub-bacia do rio Ronuro } \\
& $\begin{array}{r}\text { CFL } \\
(\%)\end{array}$ & $\begin{array}{l}\text { TCA } \\
(\%)\end{array}$ & $\begin{array}{l}\text { CA } \\
(\%)\end{array}$ & $\begin{array}{l}\text { CVS } \\
(\%)\end{array}$ & $\begin{array}{l}\text { TCA } \\
(\%)\end{array}$ \\
\hline 2004 & 13.3 & - & 8.2 & & 0.1 & - \\
$2004-08$ & 11.4 & -3.7 & 9.6 & 4.1 & 0.1 & -9.6 \\
$2008-10$ & 11.4 & 0.0 & 9.9 & 1.8 & 0.3 & 63.1 \\
$2010-12$ & 11.3 & -0.6 & 9.6 & -1.5 & 0.5 & 38.8 \\
$2012-14$ & 11.3 & -0.1 & 5.0 & -28.0 & 0.2 & -35.3 \\
\hline
\end{tabular}

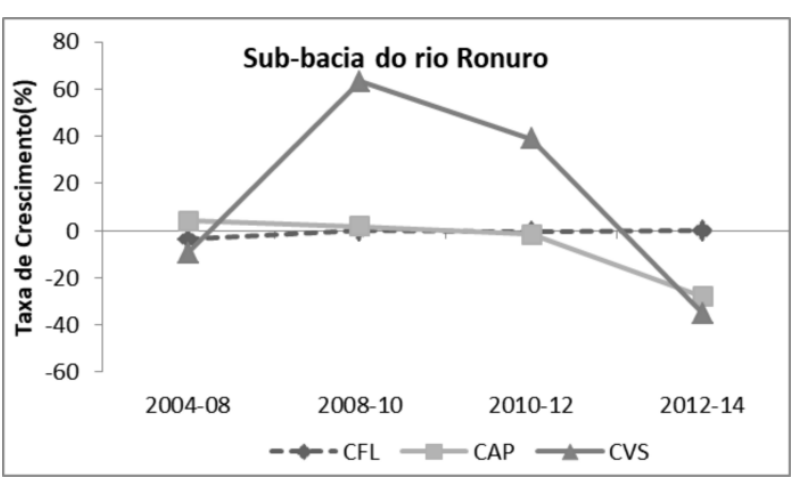

Figura 12. Comportamento da TCA da LPI para a sub-bacia do rio Fresco. Fonte: Autor, 2018.

ED da Bacia do Rio Xingu - O aumento da ED proporciona o acréscimo da fragmentação e heterogeneidade da paisagem a uma escala mais "fina" à $C F L$. Este aumento da $E D$ sugere um avanço na degradação sobre a floresta, contudo, apesar disso, o TCA da ED ao longo dos anos analisados vem diminuindo significativamente conforme visto na Tabela 15 . Em relação à CAP, houve períodos em que a TCA foi positiva de $4 \%$ e $1,9 \%$, respectivamente, para os períodos de 20042008 e 2010-2012, e taxa de redução de $-4,7 \%$ e 3,3\% para os períodos de 2008-2010 e 2012-2014, respectivamente (Figura 13). Comportamento semelhante ao da CAP foi registrado também para a CVS, porém, com variações de taxas mais expressivas (Tabela 15).

A provável consequência da redução da taxa de crescimento da CFL tenha sido a desaceleração do crescimento da atividade produtiva, que reflete também, nas oscilações ocorridas na CVS.

Tabela 15. Comportamento da ED ao nível da classe de uso do solo da bacia do rio Xingu.

\begin{tabular}{rcccccc}
\hline \multirow{2}{*}{ Período } & \multicolumn{5}{c}{ ED - Bacia do rio Xingu } \\
& $\begin{array}{c}\text { CFL } \\
(\%)\end{array}$ & $\begin{array}{c}\text { TCA } \\
(\%)\end{array}$ & $\begin{array}{c}\text { CAP } \\
(\%)\end{array}$ & $\begin{array}{c}\text { TCA } \\
(\%)\end{array}$ & $\begin{array}{c}\text { CVS } \\
(\%)\end{array}$ & $\begin{array}{c}\text { TCA } \\
(\%)\end{array}$ \\
\hline 2004 & 4.2 & - & 4.0 & - & 3.1 & - \\
$2004-08$ & 4.4 & 1.1 & 4.6 & 4.0 & 3.7 & 4.8 \\
$2008-10$ & 4.5 & 1.0 & 4.2 & -4.7 & 2.4 & -18.8 \\
$2010-12$ & 4.6 & 0.8 & 4.4 & 1.9 & 3.6 & 22.7 \\
$2012-14$ & 4.6 & 0.2 & 4.1 & -3.3 & 3.2 & -7.1 \\
\hline
\end{tabular}

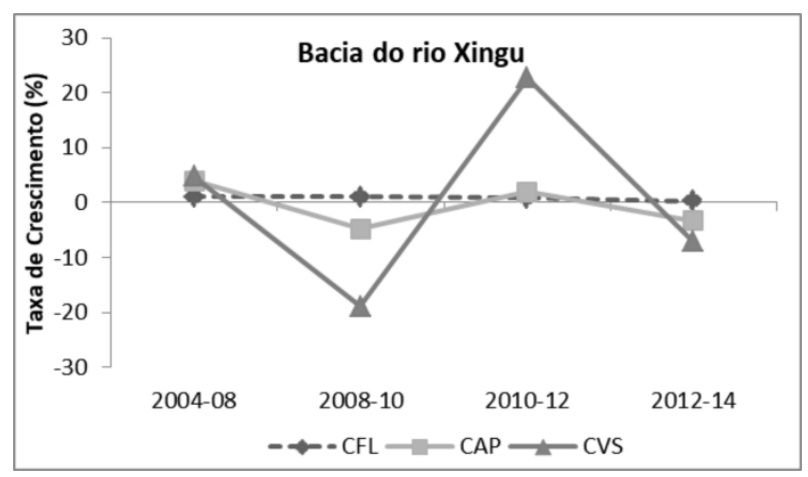

Figura 13. Comportamento da TCA da ED para a sub-bacia do rio Xingu. Fonte: Autor, 2018.

ED da Sub-bacia do Rio Fresco - A taxa de crescimento da ED para a CFL nesta sub-bacia apesar de positiva em todos os períodos (Tabela 16), sinaliza claramente à uma redução do avanço do desflorestamento, como também, sugere os dados da métrica da PLAND (Tabela 8). À CAP a métrica mostra que a ED no período de 2004-2008 registrou sua maior TCA $(10,8 \%)$, para os demais períodos, as taxas também foram positivas, porém de valores mais bem menores (Tabela 17). A CVS apresenta uma TCA bem alta $(12,8 \%)$ para o período de $2004-$ 2008 e uma redução acentua de $-13,8 \%$ no último período (Figura 14). Os resultados encontrados à CAP podem está relacionados ao padrão fundiário que se estabeleceu nesta sub-bacia, com a predominância de $85,4 \%$ de propriedade de médio e grande porte, ou seja, são espaços de cultivo que apresentam como características áreas com geometria mais regulares. 
Tabela 16. Comportamento da ED ao nível da classe de uso do solo da sub-bacia do rio Fresco.

\begin{tabular}{ccccccc}
\hline \multirow{6}{*}{ Período } & \multicolumn{6}{c}{ CFL -D Sub-bacia do rio Fresco } \\
& $\begin{array}{c}\text { TCA } \\
(\%)\end{array}$ & $\begin{array}{c}\text { CAP } \\
(\%)\end{array}$ & $\begin{array}{c}\text { TCA } \\
(\%)\end{array}$ & $\begin{array}{c}\text { CVS } \\
(\%)\end{array}$ & $\begin{array}{c}\text { TCA } \\
(\%)\end{array}$ \\
\hline 2004 & 2.9 & - & 1.8 & - & 1.2 & - \\
$2004-08$ & 3.5 & 5.0 & 2.8 & 10.8 & 1.9 & 12.8 \\
$2008-10$ & 3.9 & 5.1 & 3.1 & 5.4 & 2.0 & 2.4 \\
$2010-12$ & 4.2 & 3.6 & 3.3 & 2.5 & 2.4 & 11.7 \\
$2012-14$ & 4.5 & 3.3 & 3.6 & 4.7 & 1.8 & -13.8 \\
\hline
\end{tabular}

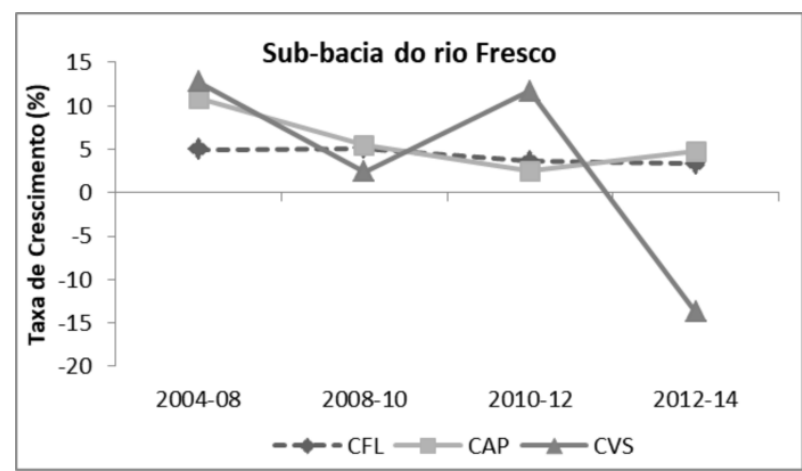

Figura 14. Comportamento da TCA da ED para a sub-bacia do rio Fresco.

Ed da Sub-bacia do Rio Curuá - o resultado da métrica de densidade de borda da CFL (Tabela 17), mostra uma leve variação positiva da TCA para os períodos de 2008-2010 e 2010-2012 de 0,7\% e $0,6 \%$, respectivamente (Figura 15 ). Em relação à CAP e CVS o comportamento foi de acréscimo da ED apenas para o período 2004-008 e 2008-2010, para os demais, as variações foram negativas (Figura 15). Nesta sub-bacia, os latifúndios concentram mais de $96 \%$ do total das áreas certificadas. Geralmente, neste tipo de propriedade, prevalecem as atividades produtivas que requerem grandes áreas desmatadas, com característica geométrica mais uniforme, o que os valores de redução da ED (Figura 16).

Tabela 17. Comportamento da ED ao nível da classe de uso do solo da sub-bacia do rio Curuá.

\begin{tabular}{cccccccc}
\hline \multirow{2}{*}{ Período } & \multicolumn{6}{c}{ ED - Sub-bacia do rio Curuá } \\
& $\begin{array}{c}\text { CFL } \\
(\%)\end{array}$ & $\begin{array}{c}\text { TCA } \\
(\%)\end{array}$ & $\begin{array}{c}\text { CAP } \\
(\%)\end{array}$ & $\begin{array}{l}\text { TCA } \\
(\%)\end{array}$ & $\begin{array}{c}\text { CVS } \\
(\%)\end{array}$ & $\begin{array}{c}\text { TCA } \\
(\%)\end{array}$ \\
\hline 2004 & 6.0 & - & 6.5 & - & 5.3 & - \\
$2004-08$ & 6.0 & 0.0 & 8.8 & 8.0 & 7.5 & 8.9 \\
$2008-10$ & 6.1 & 0.7 & 8.9 & 0.6 & 7.7 & 1.5 \\
$2010-12$ & 6.2 & 0.6 & 8.7 & -1.5 & 7.5 & -1.2 \\
$2012-14$ & 6.2 & -0.1 & 8.1 & -3.5 & 7.2 & -2.4 \\
\hline
\end{tabular}

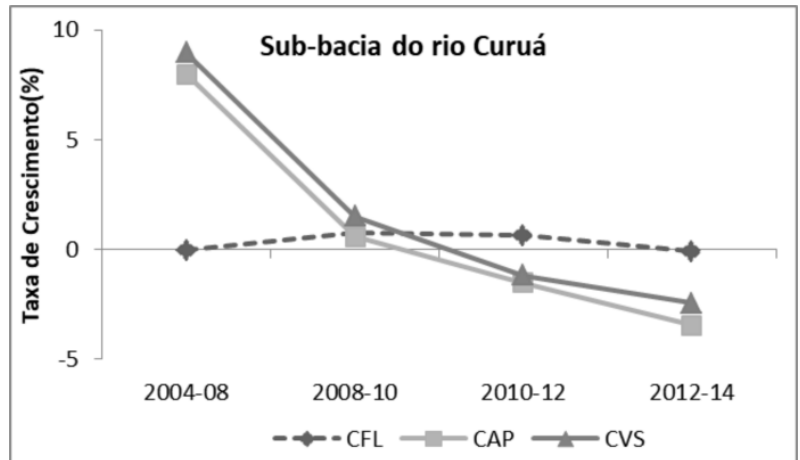

Figura 15. Comportamento da TCA da ED para a sub-bacia do rio Curuá.

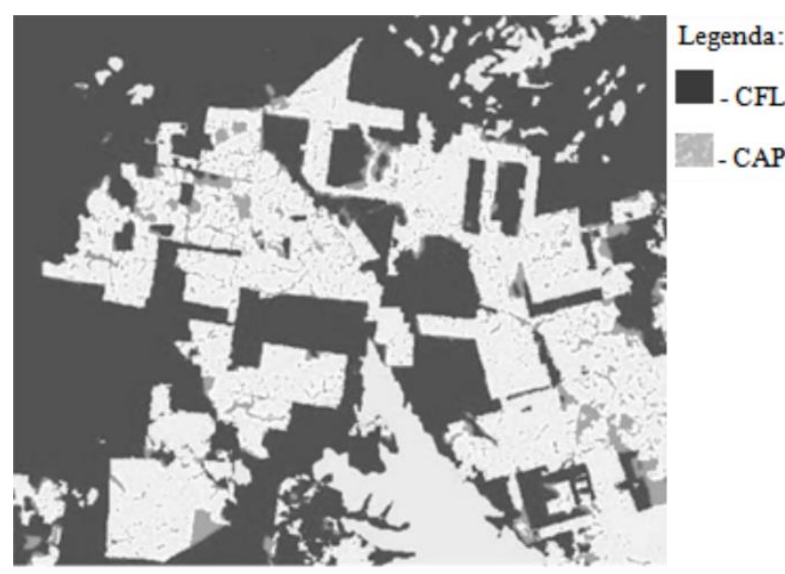

Figura 16. Padrão da geometria das áreas produtivas na sub-bacia do rio Curuá.

ED da Sub-bacia do Rio Ronuro - a TCA da ED à CFL variou expressivamente entre $2004 \mathrm{e}$ 2008 (3,2\%), e em 2012-2014 em que registrou uma variação de -1,5\% (Tabela 18). Quanto a CAP, essa registrou um aumento da TCA da ordem de 5,5\% entre 2004 e 2008, nos demais, registra sucessivas TCA negativas. A $\boldsymbol{C V} \boldsymbol{S}$ foi a que mais oscilou entre todas as classes, nos dois primeiros períodos e no último registrou TCA negativas e apenas uma positiva ocorrida entre 2010-2012 de 28\% (Figura 17).

O comportamento da TCA da ED à CVS de $-28 \%$ e de $52 \%$ estão coerentes com a redução e o crescimento da CVS registrado pela PLAND para os períodos de 2008-2010 e 2010-2012.

Tabela 18. Comportamento da ED ao nível da classe de uso do solo da sub-bacia do rio Ronuro.

\begin{tabular}{ccccccc}
\hline \multirow{6}{*}{ Período } & \multicolumn{6}{c}{ ED - Sub-bacia do rio Ronuro } \\
& $\begin{array}{c}\text { CF } \\
(\%)\end{array}$ & $\begin{array}{c}\text { TCA } \\
(\%)\end{array}$ & $\begin{array}{c}\text { CAP } \\
(\%)\end{array}$ & $\begin{array}{c}\text { TCA } \\
(\%)\end{array}$ & $\begin{array}{c}\text { CVS } \\
(\%)\end{array}$ & $\begin{array}{c}\text { TCA } \\
(\%)\end{array}$ \\
\hline 2004 & 2.0 & - & 1.8 & - & 1.3 & - \\
$2004-08$ & 2.3 & 3.2 & 2.3 & 5.5 & 1.2 & -1.9 \\
$2008-10$ & 2.3 & 0.2 & 2.1 & -4.5 & 0.6 & -28.0 \\
$2010-12$ & 2.3 & 0.8 & 2.0 & -1.8 & 1.4 & 52.0 \\
$2012-14$ & 2.2 & -1.5 & 2.0 & -0.3 & 1.2 & -7.8 \\
\hline
\end{tabular}




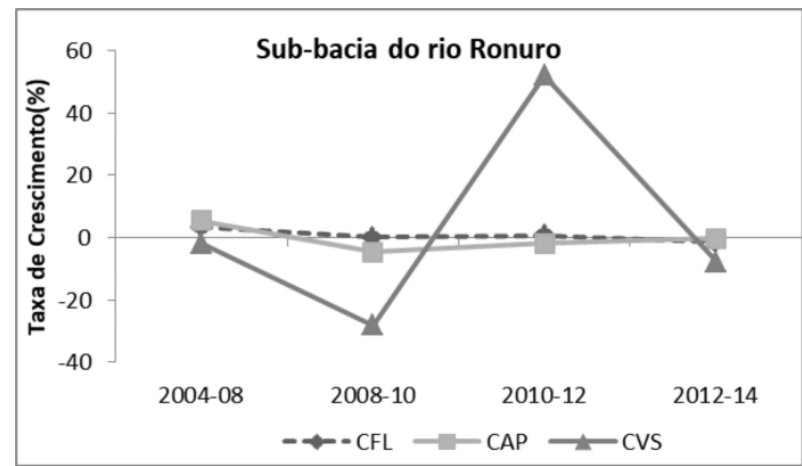

Figura 17. Comportamento da TCA da ED para a sub-bacia do rio Ronuro.

AREA_MN da Bacia do Xingu - os valores de redução gradual do tamanho da área média das manchas à CFL apresentados na Tabela 19 revela coerência quando comparado aos valores do LPI, em que ambos reforçam a tendência de redução do tamanho das manchas da CFL. O aumento do tamanho médio das manchas da CAP (Tabela 20) reforça a tendência de que as áreas produtivas estão cada vez mais conectadas entre si, formando grandes blocos de áreas desflorestadas. Esta análise é avigorada quando se observa o crescimento do LPI desta classe, com exceção para o período 2012 a 2014. Na Tabela 19, é possível verifica que CVS, também registra redução da área média das manchas para os três primeiros períodos e um aumento acentuados para os dois últimos conforme registrado no comportamento da TCA da AREA_MN (Figura 18). O fato de que tanto a CFL, CAP e a CVS tenham crescido de 2010 a 2014, pode-se afirmar que provavelmente, manchas menores de florestas e vegetação secundária tenham sido suprimidas por completo para o avanço da área produtiva, alterando desta forma o valor final do cálculo da média.

Tabela 19. Comportamento da AREA_MN ao nível da classe de uso do solo da bacia do rio Xingu.

\begin{tabular}{ccccccc}
\hline \multirow{6}{*}{ Período } & \multicolumn{6}{c}{ AREA_MN (ha) - Bacia do rio Xingu } \\
& $\begin{array}{c}\text { CFL } \\
(\%)\end{array}$ & $\begin{array}{c}\text { TCA } \\
(\%)\end{array}$ & $\begin{array}{c}\text { CAP } \\
(\%)\end{array}$ & $\begin{array}{c}\text { TCA } \\
(\%)\end{array}$ & $\begin{array}{c}\text { CVS } \\
(\%)\end{array}$ & $\begin{array}{c}\text { TCA } \\
(\%)\end{array}$ \\
\hline 2004 & 2754 & - & 317 & - & 13 & - \\
$2004-08$ & 2125 & -6.3 & 286 & -2.6 & 12 & -1.7 \\
$2008-10$ & 1751 & -9.2 & 485 & 30.3 & 11 & -5.2 \\
$2010-12$ & 1523 & -6.7 & 452 & -3.4 & 14 & 12.2 \\
$2012-14$ & 1652 & 4.1 & 596 & 14.8 & 24 & 29.9 \\
\hline
\end{tabular}

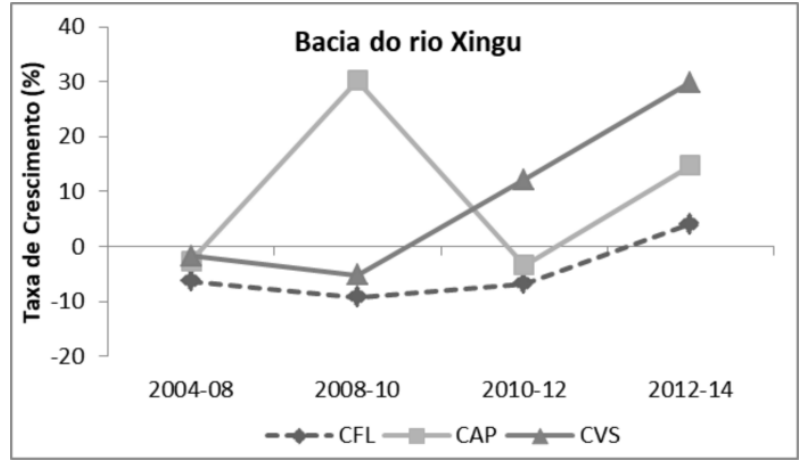

Figura 18. Comportamento da TCA da AREA_MN para a bacia do rio Xingu.

AREA_MN da Sub-bacia do Rio Fresco - o comportamento do tamanho da área média das manchas nesta sub-bacia, também, mostra uma redução acentuada à CFL (Tabela 20), contudo, os valores da TCA da AREA_MN para esta classe mostra uma queda significativa registrada no último período de $0,7 \%$ (Figura 19). A CAP apresentou comportamento inverso ao da CFL, registrando uma elevação TCA da AREA_MN para o período de 2012 a 2014 (Tabela 20), ou seja, a área produtiva vem consolidando a tendência de formação de grandes blocos de áreas desflorestadas. $\mathrm{O}$ comportamento da CVS observado na Figura 19 registra que o comportamento desta classe segue uma tendência comum, que é o inverso ao da CAP, que significa afirmar que quase sempre quando é registrado uma na variação da CAP, essa reflete de forma inversa na CVS.

Tabela 20. Comportamento da AREA_MN ao nível da classe de uso do solo da sub-bacia do rio Fresco.

\begin{tabular}{ccccccc}
\hline \multirow{2}{*}{ Período } & \multicolumn{6}{c}{ AREA_MN (ha) - Sub-bacia do rio Fresco } \\
& CFL & TCA & CAP & TCA & CVS & TCA \\
$(\%)$ & $(\%)$ & $(\%)$ & $(\%)$ & $(\%)$ \\
\hline 2004 & 5974 & - & 193 & - & 8 & - \\
$2004-08$ & 3746 & -11.0 & 180 & -1.8 & 10 & 6.2 \\
$2008-10$ & 2527 & -17.9 & 207 & 7.1 & 10 & 2.1 \\
$2010-12$ & 2171 & -7.3 & 212 & 1.3 & 14 & 20.3 \\
$2012-14$ & 2141 & -0.7 & 373 & 32.7 & 12 & -7.9 \\
\hline
\end{tabular}




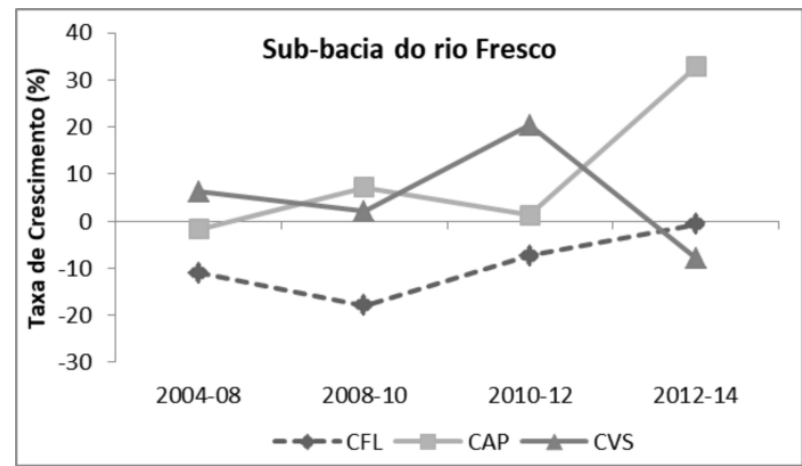

Figura 19. Comportamento da TCA da AREA_MN para a sub-bacia do rio Fresco.

AREA_MN da Sub-bacia do Rio Curuá entre 2004 e 2012 a área média da mancha à CFL teve uma redução de $47 \%$, contudo, em 2014 a TCA da AREA_MN sinalizou com um crescimento positivo de $2 \%$ (Tabela 21). Contudo, esse valor encontrado sugere que deva ter ocorrido a supressão completa de pequenas manchas de floresta, fazendo com que no cálculo desta métrica ocorresse um aumento da média, o que não significa uma recuperação da área florestada. Diferentemente nesta sub-bacia, a CAP entre 2004 e 2008 apresentou significativa redução da sua área média, porém, voltou a crescer nos períodos seguintes conforme visto na Figura 20. Esta condição observada para a CAP pode está relacionada com o pico do desmatamento registado em 2004 nos dados do PPCDAM, e os mesmo terem sido o início de um processo de aceleração das ocupações nesta subbacia e que tenha ocorrido a partir da formação de áreas produtivas menores e mais espaças uma das outras, fazendo com que o cálculo da métrica AREA_MN tenha reduzido de 2004 a 2008. Conforme observado na Figura 20, a CVS apresentou variações oposta as registradas à CAP, mas com tendência de aumento da sua área média que atingiu em 2014 a maior taxa de crescimento registrada entre todos os períodos, fato esse que se alinha com o período de queda do PIB da economia brasileira mostrado na Figura 8.

Tabela 21. Comportamento da AREA_MN ao nível da classe de uso do solo da sub-bacia do rio Curuá.

\begin{tabular}{ccccccc}
\hline \multirow{2}{*}{ Período } & \multicolumn{7}{c}{ AREA_MN (ha) - Sub-bacia do rio Curuá } \\
& $\begin{array}{c}\text { CFL } \\
(\%)\end{array}$ & $\begin{array}{c}\text { TCA } \\
(\%)\end{array}$ & $\begin{array}{c}\text { CAP } \\
(\%)\end{array}$ & $\begin{array}{c}\text { TCA } \\
(\%)\end{array}$ & $\begin{array}{c}\text { CVS } \\
(\%)\end{array}$ & $\begin{array}{c}\text { TCA } \\
(\%)\end{array}$ \\
\hline 2004 & 1419 & - & 825 & - & 9 & - \\
$2004-08$ & 928 & -10.1 & 472 & -13.1 & 9 & 2.6 \\
$2008-10$ & 836 & -5.1 & 493 & 2.2 & 10 & 0.6 \\
$2010-12$ & 748 & -5.4 & 690 & 18.3 & 9 & -4.6 \\
$2012-14$ & 809 & 4.0 & 734 & 3.2 & 18 & 43.9 \\
\hline
\end{tabular}

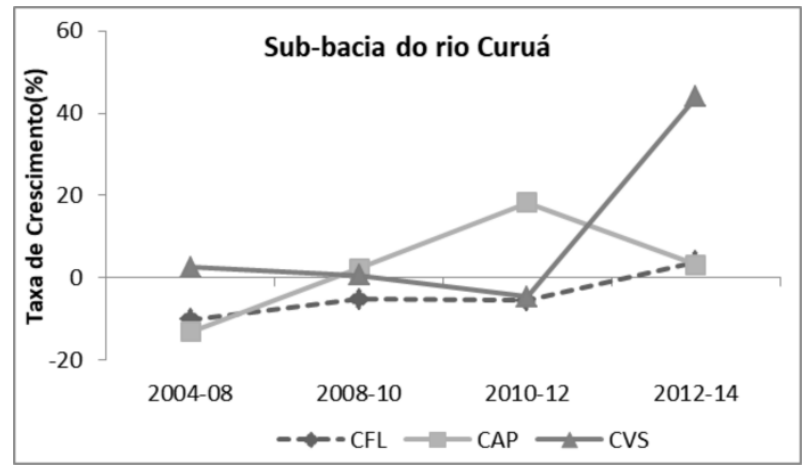

Figura 20. Comportamento da TCA da AREA_MN para a sub-bacia do rio Curuá.

ARA_MN da Sub-bacia do Rio Ronuro - as oscilações positivas observadas à CFL está relacionado com a supressão por completo das pequenas manchas de floresta, que por essa razão alteram o cálculo da média induzindo a uma percepção errada de que a área de floresta esteja se recompondo (Tabela 23). Já a CAP registra uma redução acentuada de $-116,6 \%$ da sua AREA_MN de 2004 a 2008, e um crescimento elevado de 31,9\% entre 2012 a 2014 (Figura 22). A AREA_MN da CVS nesta sub-bacia apresenta comportamento semelhante ao da CAP.

A redução de $-116,6 \%$ registrada para a CAP muito provavelmente pode está relacionada a um erro de interpretação desta classe no âmbito do TerraClass devido ser uma área de predominância de cerrado, o que dificulta a identificação na imagem de satélite de uma área produtiva.

Tabela 22. Comportamento da AREA_MN ao nível da classe de uso do solo da sub-bacia do rio Ronuro.

\begin{tabular}{ccccccc}
\hline \multirow{2}{*}{ Período } & \multicolumn{6}{c}{ AREA_MN (ha) - Sub-bacia do rio Ronuro } \\
& $\begin{array}{c}\text { CFL } \\
(\%)\end{array}$ & $\begin{array}{c}\text { TCA } \\
(\%)\end{array}$ & $\begin{array}{c}\text { CAP } \\
(\%)\end{array}$ & $\begin{array}{c}\text { TCA } \\
(\%)\end{array}$ & $\begin{array}{c}\text { CVS } \\
(\%)\end{array}$ & $\begin{array}{c}\text { TCA } \\
(\%)\end{array}$ \\
\hline 2004 & 534 & - & 1148 & - & 27 & - \\
$2004-08$ & 946 & 15.4 & 583 & -15.6 & 10 & -21.4 \\
$2008-10$ & 900 & -2.4 & 1014 & 31.9 & 21 & 41.5 \\
$2010-12$ & 657 & -14.6 & 1011 & -0.2 & 25 & 9.1 \\
$2012-14$ & 666 & 0.7 & 1482 & 21.1 & 19 & -12.5 \\
\hline
\end{tabular}




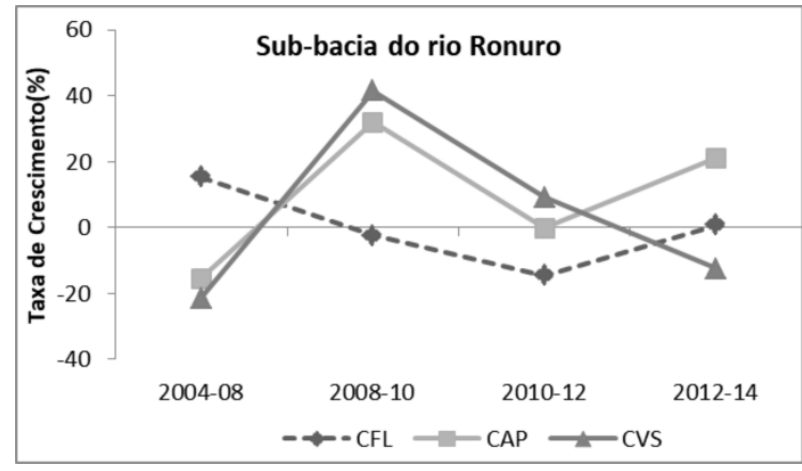

Figura 21. Comportamento da TCA da AREA_MN para a sub-bacia do rio Ronuro.

NP da Bacia do Rio Xingu - para a CFL observa-se um aumento de $75 \%$ do número de manchas entre 2004 e 2012, entretanto, em 2014 é registrada uma redução de $8,2 \%$ (Tabela 23). Contudo, é possível verificar na Figura 22, que até 2012 a taxa de crescimento era positiva e apresentava sinais de queda, em 2014, essa taxa passou a ser negativa de $-2 \%$. Já à CAP, os valores demonstram claramente que ocorreu uma redução do NP, evidenciando a tendência de homogeneidade das áreas onde está concentrada a atividade produtiva. Está situação sugere que as manchas da CAP estão cada vez mais contíguas, resultado esse, que vai ao encontro dos valores obtidos para as métricas de LPI e AREA_MN. A classe que registrou o maior NP é a de vegetação secundária, no entanto, entre 2012 a 2014 foi a que apresentou a maior redução registrando uma TCA do NP de $11,9 \%$.

Tabela 23. Comportamento da NP ao nível da classe de uso do solo da bacia do rio Xingu.

\begin{tabular}{cccccccc}
\hline \multirow{2}{*}{ Período } & \multicolumn{7}{c}{ NP - Bacia do rio Xingu } \\
& $\begin{array}{c}\text { CFL } \\
(\%)\end{array}$ & \multicolumn{1}{c}{ TCA } & \multicolumn{1}{c}{ CAP } & \multicolumn{1}{c}{ TCA } & \multicolumn{1}{c}{ CVS } & \multicolumn{1}{c}{ TCA } \\
$(\%)$ & \multicolumn{1}{c}{$(\%)$} & \multicolumn{1}{c}{$(\%)$} \\
\hline 2004 & 11474 & - & 19079 & - & 81347 & - \\
$2004-08$ & 14554 & 6.1 & 23106 & 4.9 & 96964 & 4.5 \\
$2008-10$ & 17562 & 9.8 & 14939 & -10.3 & 65910 & -9.2 \\
$2010-12$ & 20098 & 7.0 & 15066 & 0.2 & 92794 & 8.9 \\
$2012-14$ & 18440 & -4.2 & 11661 & -6.2 & 55879 & -11.9 \\
\hline
\end{tabular}

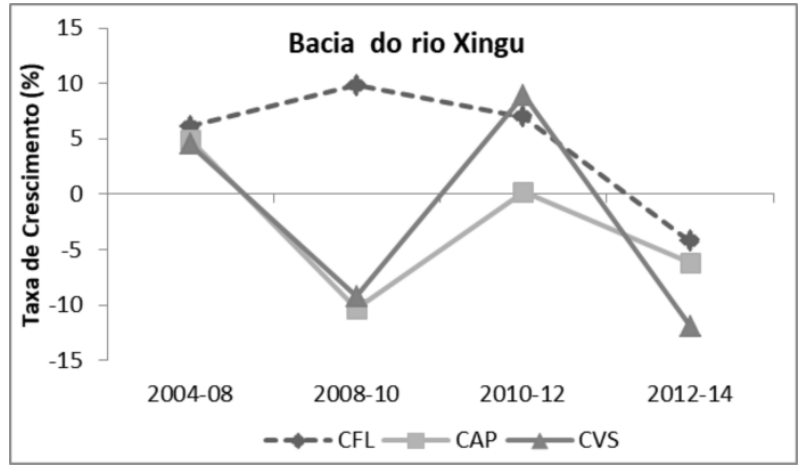

Figura 22. Comportamento da TCA da NP para a bacia do rio Xingu.

NP da Sub-bacia do Rio Fresco - foi a subbacia que apresentou o maior crescimento do NP à CFL entre os anos de 2004 a 2014, registrou um aumento de 160,7\% (Tabela 10). Contudo, observase um decréscimo do número de manchas ao longo dos anos conforme o comportamento da TCA do NP observado na Figura 23.

Os resultados mostram um aumento do número de manchas para a CFL e de CVS, porém, a TCA do NP registra uma redução dessa fragmentação ao longo dos últimos anos (Figura 23). Em relação a CAP, a mesma apresenta um comportamento inverso no que diz respeito a redução do NP, fato que reforça a tendência de homogeneidade dessas manchas tornando-se grandes áreas produtivas contiguas.

Tabela 24. Comportamento da NP ao nível da classe de uso do solo da sub-bacia do rio Fresco.

\begin{tabular}{rrrrrrrr}
\hline \multirow{2}{*}{ Período } & \multicolumn{6}{c}{ CFL - Sub-bacia do rio Fresco } \\
& \multicolumn{1}{c}{$\begin{array}{c}\text { TCA } \\
(\%)\end{array}$} & \multicolumn{1}{c}{ CAP } & \multicolumn{1}{c}{ TCA } & \multicolumn{1}{c}{ CVS } & TCA \\
\hline (\%) & \multicolumn{1}{c}{$(\%)$} & \multicolumn{1}{c}{$(\%)$} \\
\hline 2004 & 537 & - & 729 & & 2996 & - \\
$2004-08$ & 832 & 11.6 & 1179 & 12.8 & 4137 & 17.5 \\
$2008-10$ & 1218 & 21.0 & 1207 & 1.2 & 4442 & 3.6 \\
$2010-12$ & 1403 & 7.3 & 1211 & 0.2 & 4726 & 3.1 \\
$2012-14$ & 1400 & -0.1 & 874 & -15.0 & 3835 & -9.9 \\
\hline
\end{tabular}

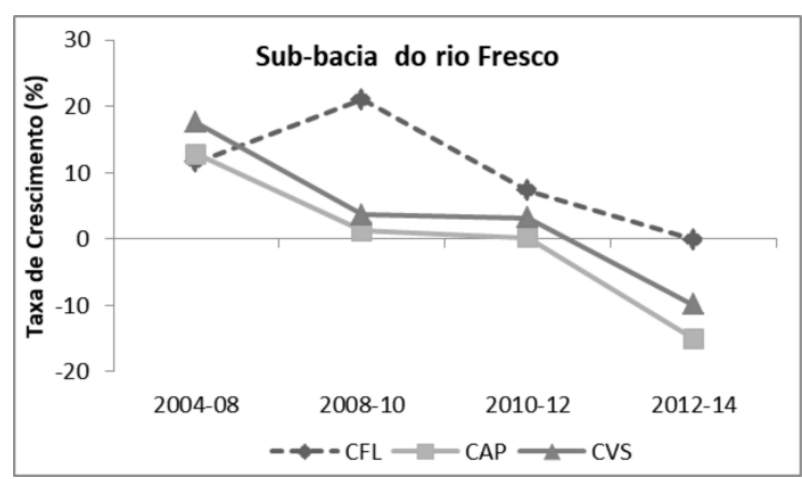

Figura 23. Comportamento da TCA da NP para a sub-bacia do rio Fresco. 
NP da Sub-bacia do Rio Curuá acompanhando a tendência das demais áreas, onde a CFL registra crescimento de $74,2 \%$ entre os anos de 2014 a 2012, e que em 2014 apresentou uma redução de $7,8 \%$ (Tabela 25 ).

A CAP registrou crescimento do NP entre os anos de 2004 e 2008 a uma TCA de 18,4\% (Figura 7), entretanto, entre 2008 e 2014 ocorreu uma redução significativa de $36,7 \%$ do NP. Esta redução é influenciada pela estrutura fundiária da sub-bacia, onde mais $96 \%$ do total dos imóveis regularizados estão concentrados na categoria de latifúndio, as quais têm como principal característica a produção voltada para o agronegócio, que é um setor da economia onde as atividades produtivas são desenvolvidas em grande escala.

A CVS registra crescimento do NP até o ano de 2012, porém, a TCA do NP indica a tendência de redução dessa fragmentação (Figura 24). Em 2014, ocorre uma queda do NP ocasionada provavelmente, pelo aumento de área desta classe conforme registrado pelo PLAND para este mesmo ano. A causa desse processo está diretamente relacionada com a desaceleração da atividade produtiva que em épocas de crise financeira lava ao abandono de parte das áreas produtivas.

Tabela 25. Comportamento da NP ao nível da classe de uso do solo da sub-bacia do rio Curuá.

\begin{tabular}{rcccccc}
\hline \multirow{2}{*}{ Período } & \multicolumn{7}{c}{ NP - Sub-bacia do rio Curuá } \\
& $\begin{array}{c}\text { CFL } \\
(\%)\end{array}$ & $\begin{array}{c}\text { TCA } \\
(\%)\end{array}$ & $\begin{array}{c}\text { CAP } \\
(\%)\end{array}$ & $\begin{array}{c}\text { TCA } \\
(\%)\end{array}$ & CVS $(\%)$ & $\begin{array}{c}\text { TCA } \\
(\%)\end{array}$ \\
\hline 2004 & 1771 & - & 1332 & - & 16489 & - \\
$2004-08$ & 2517 & 9.2 & 2620 & 18.4 & 19167 & 3.8 \\
$2008-10$ & 2779 & 5.1 & 2522 & -1.9 & 19612 & 1.2 \\
$2010-12$ & 3085 & 5.4 & 1832 & -14.8 & 20894 & 3.2 \\
$2012-14$ & 2843 & -4.0 & 1659 & -4.8 & 13110 & -20.8 \\
\hline
\end{tabular}

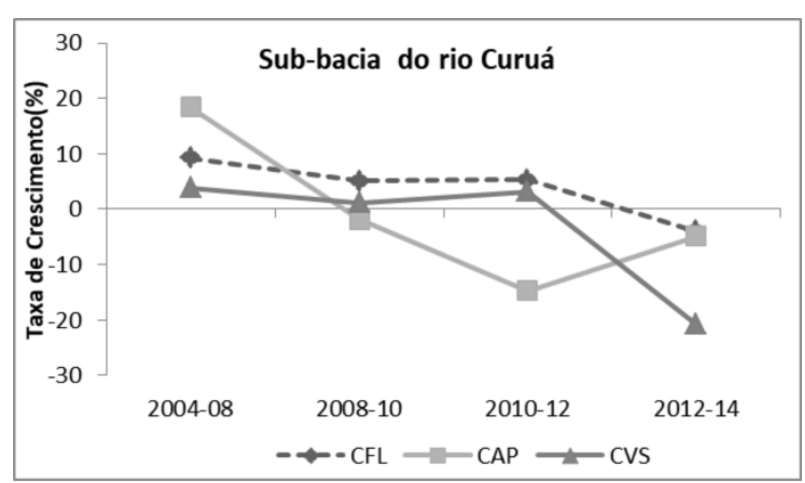

Figura 24. Comportamento da TCA da NP para a sub-bacia do rio Curuá.

NP da Sub-bacia do Rio Ronuro - devido a área desta sub-bacia ser considerada de transição entre floresta e cerado, com predominância deste último, o NP registrado para a CLF é muito pequena, e teve uma redução de $32,1 \%$ entre os anos de 2004 a 2014, registrando neste último ano apenas 89 manchas de floresta (Tabela 26). A CAP, não diferentemente das outras sub-bacias, registrou redução do NP atingindo no ano de 2014 um total de apenas 38 manchas. Este número tão pequeno pode ser consequência da dificuldade encontrada na classificar do uso do solo em área de cerrado. A CVS apresentou oscilações sempre acompanhando as variações registradas na CAP (Figura 25).

De um modo geral, a redução do NP à CFL está relacionada com a supressão de pequenos fragmentos o que não significa nenhuma melhora nas condições ambientais da sub-bacia, pelo contrário, no geral reflete na redução da área desta classe.

Tabela 26. Comportamento da NP ao nível da classe de uso do solo da sub-bacia do rio Ronuro.

\begin{tabular}{ccccccc}
\hline \multirow{2}{*}{ Período } & \multicolumn{6}{c}{ NP - Sub-bacia do rio Ronuro } \\
& $\begin{array}{c}\text { CFL } \\
(\%)\end{array}$ & $\begin{array}{c}\text { TCA } \\
(\%)\end{array}$ & $\begin{array}{c}\text { CAP } \\
(\%)\end{array}$ & $\begin{array}{c}\text { TCA } \\
(\%)\end{array}$ & $\begin{array}{c}\text { CVS } \\
(\%)\end{array}$ & $\begin{array}{c}\text { TCA } \\
(\%)\end{array}$ \\
\hline 2004 & 131 & - & 39 & & 189 & - \\
$2004-08$ & 64 & -16.4 & 96 & 25.3 & 317 & 13.8 \\
$2008-10$ & 67 & 2.3 & 56 & -23.6 & 130 & -36.0 \\
$2010-12$ & 91 & 16.5 & 53 & -2.7 & 261 & 41.7 \\
$2012-14$ & 89 & -1.1 & 38 & -15.3 & 222 & -7.8 \\
\hline
\end{tabular}

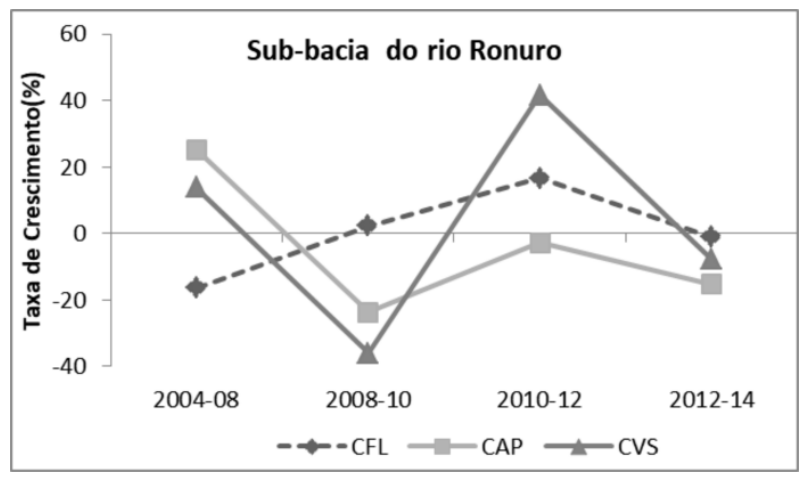

Figura 25. Comportamento da TCA da NP para a sub-bacia do rio Ronuro.

LSI da Bacia do Rio Xingu - o comportamento da LSI apresentado na Tabela 27 mostra a existência de tendência de crescimento da desagregação da CFL, decorrente das intervenções antrópicas ocorridas na paisagem da bacia. Tanto à CAP quanto CVS, apresentam índices bastante elevados e se observa uma oscilação constante da TCA (Figura 26). A tendência de desagregação da área produtiva apontada pelos valores do LSI deve ser vista com cautela, pois em razão do tamanho da área da bacia do rio Xingu e da existência de um número significativo de áreas protegidas, estes fatos acabam funcionando como elemento de dispersão 
das manchas das áreas produtivas, influenciando desta maneira no resultado do LSI. A homogeneização a CPA fica mais perceptível quando elas passam a ser analisada no contesto das sub-bacias.

Tabela 27. Comportamento da LSI ao nível da classe de uso do solo da bacia do rio Xingu.

\begin{tabular}{ccccccc}
\hline \multirow{2}{*}{ Período } & \multicolumn{6}{c}{ LSI - Bacia do rio Xingu } \\
& $\begin{array}{c}\text { CFL } \\
(\%)\end{array}$ & $\begin{array}{c}\text { TCA } \\
(\%)\end{array}$ & $\begin{array}{c}\text { CAP } \\
(\%)\end{array}$ & $\begin{array}{c}\text { TCA } \\
(\%)\end{array}$ & $\begin{array}{c}\text { CVS } \\
(\%)\end{array}$ & $\begin{array}{c}\text { TCA } \\
(\%)\end{array}$ \\
\hline 2004 & 86.3 & - & 182.0 & - & 330.4 & - \\
$2004-08$ & 91.0 & 1.3 & 203.6 & 2.8 & 377.6 & 3.4 \\
$2008-10$ & 93.1 & 1.1 & 176.7 & -3.5 & 318.2 & -4.2 \\
$2010-12$ & 94.8 & 0.9 & 189.1 & 1.7 & 359.7 & 3.1 \\
$2012-14$ & 95.5 & 0.3 & 175.1 & -1.9 & 308.4 & -3.8 \\
\hline
\end{tabular}

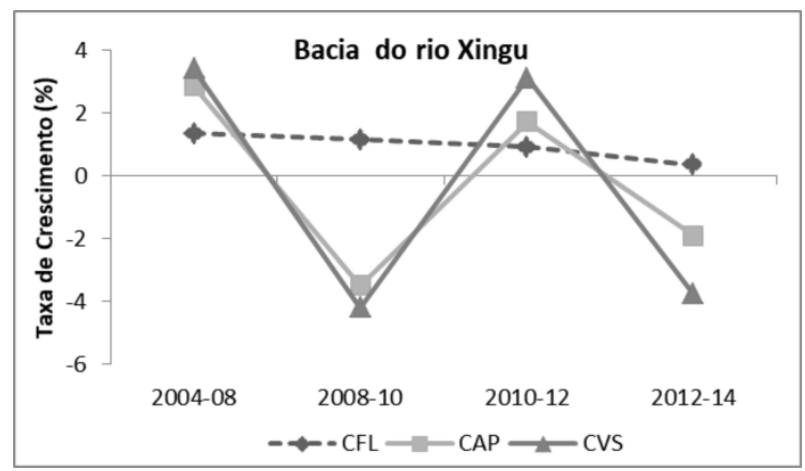

Figura 26. Comportamento da TCA da LSI para a bacia do rio Xingu.

LSI da Sub-bacia do Rio Fresco - apesar do LSI da CFL ter registrado crescimento do índice entre 2004 a 2014, o que indica um aumento da desagregação, a TCA da LSI demonstra tendência de redução desses valores (Tabela 28 e Figura 27). A TCA da CAP e da CVS apresentou comportamento semelhante, em ambas as classes o LSI registrou crescimento entre 2004 a 2012 e redução em 2012 a 2014. O índice de desagregação da floresta desta sub-bacia mostra uma melhor condição do que a da bacia do Xingu, umas das razões é a disposição geográfica das áreas protegidas, que formam um bloco único e contíguo, enquanto que na bacia do Xingu, as áreas protegidas se intercalam entre as áreas de atividade produtiva (Figura 28).
Tabela 28. Comportamento da LSI ao nível da classe de uso do solo da sub-bacia do rio Fresco.

\begin{tabular}{ccccccc}
\hline \multirow{6}{*}{ Período } & \multicolumn{6}{c}{ CSI - Sub-bacia do rio Fresco } \\
& $\begin{array}{c}\text { CFL } \\
(\%)\end{array}$ & $\begin{array}{c}\text { TCA } \\
(\%)\end{array}$ & $\begin{array}{c}\text { CAP } \\
(\%)\end{array}$ & $\begin{array}{c}\text { TCA } \\
(\%)\end{array}$ & $\begin{array}{c}\text { CVS } \\
(\%)\end{array}$ & $\begin{array}{c}\text { TCA } \\
(\%)\end{array}$ \\
\hline 2004 & 16.5 & - & 44.6 & - & 68.9 & - \\
$2004-08$ & 19.9 & 4.8 & 54.6 & 5.2 & 84.2 & 5.1 \\
$2008-10$ & 21.8 & 4.9 & 56.1 & 1.3 & 83.4 & -0.4 \\
$2010-12$ & 23.4 & 3.6 & 58.0 & 1.7 & 84.0 & 0.3 \\
$2012-14$ & 25.0 & 3.4 & 56.5 & -1.4 & 75.2 & -5.4 \\
\hline
\end{tabular}

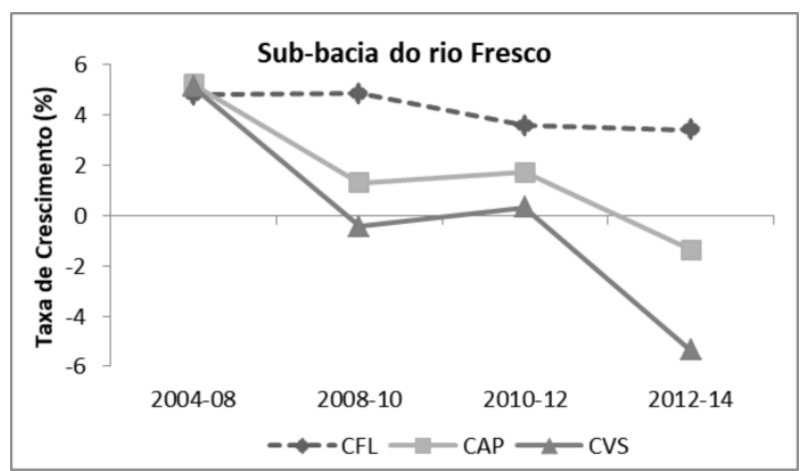

Figura 27. Comportamento da TCA da LSI para a sub-bacia do rio Fresco.
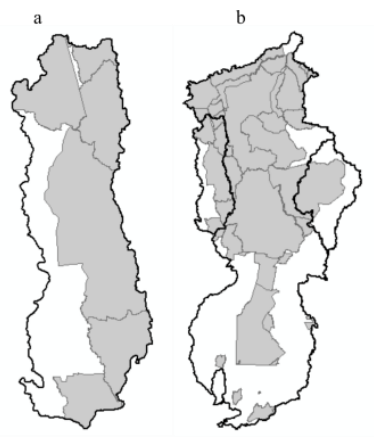

Figura 28. Disposição geográfica das áreas protegidas na sub-bacia do rio Fresco (a) e na bacia do rio Xingu (b).

LSI da Sub-bacia do Rio Curuá - das três sub-bacias a do rio Curuá foi a que apresentou o maior índice de desagregação para a CFL, contudo a TCA da LSI mostra uma tendência de redução da dispersão dessas manchas (Tabela 29). A redução da TCA é explicada pela estrutura fundiária atual, onde praticamente, a única grande área de floresta existente é da Terra Indígena, conforme mostra a Figura 29, as demais áreas no entorno da mesma já foram ocupadas e sua floresta praticamente quase toda suprimida. Portanto, a diminuição da TCA do LSI da CFL não significa necessariamente dizer que a floresta está menos desagregada. Já a LSI da CVS registrou valores bastante elevados entre 2004 e 2012, indicando grande dispersão de suas manchas, contudo, em 2014, ocorreu uma melhora que pode também, ser observado principalmente na parte sul da sub-bacia (Figura 30). 


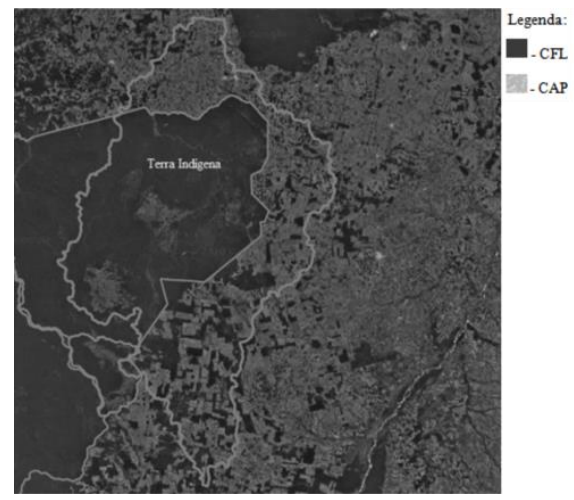

Figura 29. Situação da ocupação antrópica na sub-bacia do rio Curuá.

Tabela 29. Comportamento da LSI ao nível da classe de uso do solo da sub-bacia do rio Curuá.

\begin{tabular}{cccccccc}
\hline \multirow{2}{*}{ Período } & \multicolumn{6}{c}{ LSI - Sub-bacia do rio Curuá } \\
& $\begin{array}{c}\text { CFL } \\
\text { (\%) }\end{array}$ & $\begin{array}{l}\text { TCA } \\
(\%)\end{array}$ & $\begin{array}{l}\text { CAP } \\
(\%)\end{array}$ & \multicolumn{1}{c}{ TCA } & \multicolumn{1}{c}{$\begin{array}{l}\text { CVS } \\
(\%)\end{array}$} & $\begin{array}{c}\text { TCA } \\
(\%)\end{array}$ \\
\hline 2004 & 41.9 & - & 67.4 & - & 151.9 & - \\
$2004-08$ & 43.3 & 0.8 & 86.0 & 6.3 & 188.7 & 5.6 \\
$2008-10$ & 44.1 & 0.9 & 86.8 & 0.4 & 191.1 & 0.6 \\
$2010-12$ & 44.7 & 0.8 & 83.6 & -1.9 & 189.5 & -0.4 \\
$2012-14$ & 44.8 & 0.0 & 79.4 & -2.5 & 158.3 & -8.6 \\
\hline
\end{tabular}

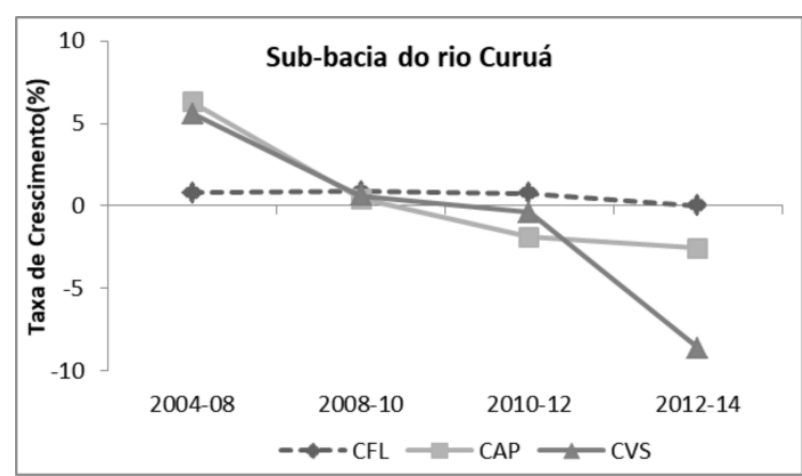

Figura 30. Comportamento da TCA da LSI para a sub-bacia do rio Curuá.

LSI da Sub-bacia do Rio Ronuro - devido à baixa quantidade de manchas de floresta existente nesta sub-bacia (Tabela 30), o LSI da CFL registrou valores bastante reduzidos, mostrando que existe uma baixa dispersão entre elas conforme mostra a Figura 31. A mesma situação também se repete para a CVS, porém, com duas situações bem distintas, uma com variação acentuada da TCA de $-25 \%$ registrada no período de 2008 a 2010, e a outra, registrada no período de 2010 a 2012 de $23 \%$ (Figura 31). Observa-se que ambas as oscilações da TCA do LSI coincidem com as flutuações do PIB brasileiro mostrado na Figura 8.
Tabela 30. Comportamento da LSI ao nível da classe de uso do solo da sub-bacia do rio Ronuro.

\begin{tabular}{|c|c|c|c|c|c|c|}
\hline \multirow[b]{2}{*}{ Período } & \multicolumn{6}{|c|}{ LSI - Sub-bacia do rio Ronuro } \\
\hline & $\begin{array}{l}\text { CFL } \\
(\%)\end{array}$ & $\begin{array}{l}\text { TCA } \\
(\%)\end{array}$ & $\begin{array}{l}\text { CAP } \\
(\%)\end{array}$ & $\begin{array}{l}\text { TCA } \\
(\%)\end{array}$ & $\begin{array}{l}\text { CVS } \\
(\%)\end{array}$ & $\begin{array}{c}\mathrm{TCA} \\
(\%)\end{array}$ \\
\hline 2004 & 7.8 & - & 8.9 & - & 17.0 & - \\
\hline 2004-08 & 9.3 & 4.7 & 9.8 & 2.4 & 19.7 & 3.8 \\
\hline $2008-10$ & 9.4 & 0.2 & 9.0 & -4.1 & 11.1 & -25.0 \\
\hline $2010-12$ & 9.5 & 0.9 & 8.9 & -0.6 & 16.8 & 23.0 \\
\hline 2012-14 & 9.3 & -1.2 & 8.7 & -1.4 & 17.7 & 2.6 \\
\hline
\end{tabular}

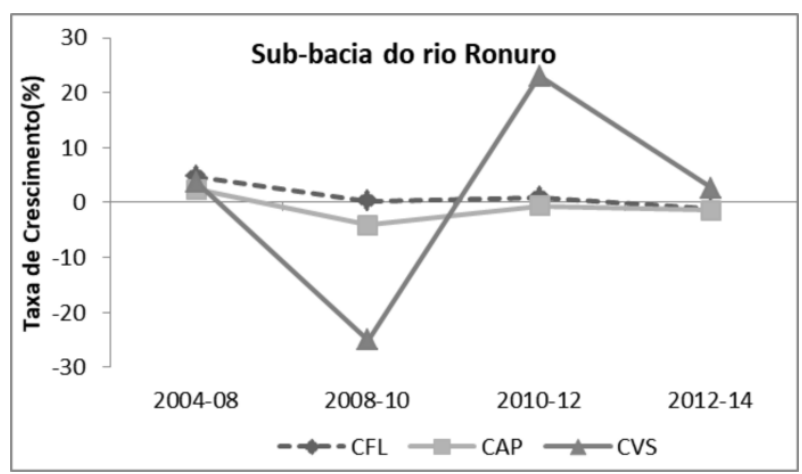

Figura 31. Comportamento da TCA da LSI para a sub-bacia do rio Ronuro.

\section{Conclusão}

Os dados da estrutura fundiária da bacia do rio Xingu mostram que $73,7 \%$ de sua área são de terras públicas, e desse total, $52,1 \%$ são de áreas especialmente protegidas (terra indígena, unidade de conservação e terra militar). Desta forma, conclui-se que está condição vem contribuindo parcialmente para conter o avanço do desmatamento sobre as áreas de vegetação primitiva, entretanto, os resultados mostram que somente esse mecanismo não é capaz de manter a integridade original da paisagem da bacia do rio Xingu.

Com relação às áreas de destinação privada, cerca de $18,8 \%$ da área da bacia está ocupada por imóveis privados já certificados pelo INCRA, onde, apenas 3,6\% são áreas destinadas a assentamentos. Cerca de $30,5 \%$ dos imóveis da bacia do rio Xingu e 34\% dos imóveis da sub-bacia do rio Curuá são classificados como latifúndios, sendo que esses percentuais, correspondem respectivamente a $95,1 \%$ e $96,1 \%$ da área total de todos os imóveis certificados. Desta forma, admite-se que estrutura fundiária no tocante as áreas sobre o controle do particular, tem características predominantemente voltada à concentração de grandes áreas sob o domínio de grandes latifúndios, os quais apresentam como características predominantes, o uso de grandes extensões de áreas para o desenvolvimento de atividade produtivo voltado ao agronegócio. 
A sub-bacia do rio Fresco é a que apresenta a melhor situação de distribuição de terras privadas entre os imóveis certificados, deste, $55 \%$ é classificada como média propriedade e acumulam 69,9\% das áreas destinadas aos imóveis privados e certificados.

A sub-bacia do rio Runoro foi a que apresentou a maior concentração de terras certificadas classificadas como latifúndio (90,6\%), as quais, acumulam cerca de $96,1 \%$ das áreas dos imóveis privados e certificados, contudo, é a que tem uma menor quantidade de área especialmente protegida. Desta forma, conclui-se que entre as três sub-bacias estudadas, a do rio Ronuro é a que apresenta maior risco de comprometimento de um adequado equilíbrio ambiental devido a características de sua ocupação fundiária e a falta de áreas públicas especialmente protegidas.

Os resultados das métricas de paisagem mostram que o período de 2004 a 2008, foi o mais crítico em termos de degradação ambiental, tanto no âmbito da bacia do rio Xingu, como também, nas sub-bacias dos rios Fresco, Curuá, e Runoro.

Foi constatado também, que a atividade produtiva instalada na região oscilou em termo de crescimento e retração ao longo dos anos, e que o declínio da sua expansão ao logo dos anos, favoreceu para reduzir a pressão antrópica sobre as áreas de vegetação primitiva.

Os dados indicam ainda, que o processo de crescimento da atividade produtiva vem ocasionando a fragmentação da floresta, proporcionando o aumento do número de manchas e do comprimento de bordas. São justamente ao longo destas bordas que são formadas dentro das florestas, que ocorrem uma maior exposição aos ventos, variações micrometeorológicas acentuadas em distâncias relativamente curtas, maior exposição do solo, e consequentemente, menor capacidade de infiltração (Cheng et al. 2002; Best et al. 2003).

$\mathrm{O}$ aumento do número de manchas (fragmentos) de floresta mostra claramente que a atividade produtiva vem avançando sobre a floresta, comprometendo o tamanho de suas áreas, aumentando o seu efeito de borda, elevando a perda da diversidade biológica e diminuição da proteção do solo.

Os resultados encontrados por Costa et al. (2015) de que a remoção da floresta implica não apenas na sua perda, mas também numa redução do tamanho das manchas, se confirma neste estudo quando observamos que no período de 2004 a 2014 a percentagem da maior mancha da floresta na bacia do rio Xingu sofreu redução de $1,6 \%$. Situação semelhante foi constatada na sub-bacia do rio
Curuá, porém, de maneira mais intensa, com registro de redução de 7,4\% ao longo de 10 anos.

Com isso, podemos afirmar que o resultado de densidade de borda da classe de floresta é coerentes com a afirmação de Broadbent et al. (2008), em que a fragmentação na Amazônia está criando grandes áreas de floresta susceptíveis aos efeitos de bordas, sendo que a sub-bacia do rio Curuá é a que apresenta maior comprometimento, registrando cerca de 6,2 m/ha de bordas em 2014 .

Com base nesses resultados pode-se inferir que os efeitos dos desmatamentos em ambiente amazônico poderão acarretar alterações no processo hidrológico, principalmente, poderá proporcionar uma resposta hidrológica mais rápida nos valores de escoamento superficial e lateral devido à diminuição dos processos de interceptação e de infiltração (Nóbrega, 2014).

A metodologia empregada neste estudo, baseada na técnica de análise de métricas de paisagem se mostrou satisfatória na identificação das alterações advindas da dinâmica do uso e ocupação do solo no contexto de bacia hidrográfica.

\section{Referencias}

Almeida, C. A.; Coutinho, A. C.; Esquerdo, J. C. D. M.; Adami, M.; Venturieri, A.; Diniz, C. G.; Dessay, N.; Durieux, L.; G., A. R. 2016. High spatial resolution land use and land cover mapping of the Brazilian Legal Amazon in 2008 using Landsat-5/TM and MODIS data. Acta Amazonica 46, 291-302.

Andren, H. 1994. Effects of habitat fragmentation on birds and mammals in landscapes with different proportions of suitable habitat - a review. Wiley - Nordic Society Oikos 71, 355366.

Ayres, J. M. 1995. As matas de várzea do Mamirauá: médio Solimões. 2. ed. Brasília: CNPq/Sociedade Civil Mamirauá.

Becker, B. 1990. Amazônia. São Paulo: Editora Ática.

Best, A.; Zhang, L.; Mcmahom, T.; Western, A. R. 2003. A critical review of paired catchment studies with reference to seasonal flow and climatic variability. Melbourne: University of Melbourne.

Brasil. Lei ${ }^{\circ}$ 4.504, de 30 de novembro de 1964. Estatuto da Terra. Disponível em: < http://www.planalto.gov.br/ccivil_03/Leis/L450 4.htm>. Acesso em 15 fev. 2018.

Brasil. Ministério das Minas e Energia. Secretaria Geral. Projeto RADAMBRASIL. Levantamento de Recursos Naturais, Vols. 1-23. Ministério das Minas e Energia, Departamento Nacional de 
Produção Mineral (DNPM) Rio de Janeiro, RJ, Brasil. 1973-1985.

Broadbent, E.; Asner, G.; Keller, M.; et al. 2008. Forest fragmentation and edg e effects from deforestation and selective logging in the Brazilian Amazon. Biological Conservation 141, 1745-1757, Disponível em: <http://linkinghub.elsevier.com/retrieve/pii/S00 06320708001377>. Acesso em: 3 de out. 2017

Instituto Nacional de Colonização e Reforma Agrária. Tabela com módulo fiscal dos municípios. 2013. Disponível em: < http://www.incra.gov.br/tabela-modulo-fiscal>. Acesso em 15 fev. 2018.

Cabacinha, C.D.; Castro, S.S.; Gonçalves, D.A. 2010. Análise da estrutura da paisagem da alta bacia do Rio Araguaia na savana brasileira. Revista Floresta 40, 675-690.

Cheng, J.D.; Lin, L.L.; Lu, H. S. 2002. Influence of forests on water flows from headwater watersheds in Taiwan. Forest Ecology and Management 165, 11-28,

Costa,O.B.; Matricardi, E.A.T.; Pires, J.S.R., 2015. Análise do Processo de Fragmentação da Floresta nos Municípios de Corumbiara e Buritis - RO. Revista Floresta e Ambiente 22 (3). Disponível em: http://dx.doi.org/10.1590/S010340142002000200004. Acesso: 22 mar..2018.

Farina, A. Landscape Ecology in Action. Dordrecht: Kluwer Academic Publishers, 2000.

Fearnside, P. M. 2001. Soybean cultivation as a threat to the environment in Brazil. Environmental Conservation 28, 23-38.

2005. Deforestation in Brazilian Amazonia: History, rates and consequences. Conservation Biology 19, 680-688.

Forman, R.T. 1999. Land Mosaics - The ecology of landscapes and regions. $5^{\mathrm{a}}$ ed. Cambridge University Press: Cambridge.

Forman, R.T.T. and M. Godron. 1986. Landscape ecology. John Wiley \& Sons, New York. 620 pp.

Gyawali, R.; Greb, S.; Block, P. , 2015. Temporal Changes in Streamflow and Attribution of Changes to Climate and Landuse in Wisconsin Watersheds. Journal of the American Water Resources Association 51, 1138-1152.

Hamilton, L.S. 1990. Tropical forests: identifying and clarifying issues. an overview paper. In. Markham, Adam. Tropical Forests Task Force of the Pacific Economic Cooperation Council. Kuala Lampur: Issues for the Tropical Forests Task Force of the Pacific Economic Cooperation Council.
Instituto de Economia Aplicada (Brasil). IPEA: texto para discussão. Brasília: Instituto de Economia Aplicada, 2015. p. 12-41. ISBN: 9788587545442 (v.1).

Khanna, J. et al. Regional dry-season climate changes due to three decades of Amazonian deforestation. Nature Climate Change 7, 200204, 2017.

Lin, Y.; Hong, N.; Wu, P.; Wu, C.; Verburg, P.H., 2007. Impacts of land use change scenarios on hydrology and land use patterns in the $\mathrm{Wu}-\mathrm{Tu}$ watershed in Northern Taiwan. Landscape and Urban Planning 80, 111-126.

McGarigal K. Fragstats: Fragstats help - versão 4.2. Computer software program produced by the author at the University of Massachusetts. Massachusetts: Amherst; 2013. 182 p.

Metzger J. P. Conservation issues in the Brazilian Atlantic Forest. Biological Conservation 2009; 142(6): $1138-1140$. http://dx.doi.org/10.1016/j.biocon.2008.10.012.

Nobre, A. D. O Futuro Climático da Amazônia: relatório de avaliação científica. Articulación Regional Amazônica - ARA. São José dos Campos: CPTEC/INPE. 2014. 42 p.

Nobre, C. A.; S., G.; Salazar, L. Mudanças Climáticas e Amazônia. Ciência e Cultura 59, 22-27, jul. 2007. Disponível em: $<$ http://cienciaecultura.bvs.br/pdf/cic/v59n3/a12 v59n3.pdf >. Acesso em: 02 set. 2017.

Nóbrega, R.S., 2014. Impacto do desmatamento e de mudanças climáticas nos recursos hídricos na Amazônia Ocidental utilizando o modelo SLIRP. Tese (Doutorado). Departamento de Ciências Geográficas, Universidade Federal de Pernambuco.

Paula, L. F.; Pires, M. 2017. Crise e perspectivas para a economia brasileira. Estudo Avançados 31, 125-144.

Rice, J. S. et al. 2015. Continental U.S. streamflow trends from 1940 to 2009 and their relationships with watershed spatial characteristics. Water Resources Research 6262-6275.

Rodriguez, J.M.M.; Silva, E.V.A. 2002. Classificação das paisagens a partir de uma visão geossistêmica. In: Mercartor - Revista de Geografia da UFC.

Santos, C., Lima, A., Serrão, E., Farias, M., Wanzeler, R., \& Araujo, I. 2016. Modelo de previsão fluviométrica para o rio Xingu na cidade de Altamira - PA. Revista Internacional de Ciências 6, $230 \quad-\quad 243$. doi:https://doi.org/10.12957/ric.2016.24829 
Silva, M.S.F; Souza, R.M. 2014. Spatial patterns of forest fragmentation in the Flona Ibura - Sergipe. Mercator 13121-137.

Silva, Lélis; Pena, H.W.A.; Oliveira, F.A., 2015. A dinâmica da ocupação da Amazônia brasileira: do interesse político e econômico aos conflitos socioambientais. Revista Caribeña de Ciencias Sociales [online]. Disponível em: $\mathrm{http}: / /$ caribeña.eumed.net/conflitossocioambientais/. Acesso em: 08 set. de 2018.

Spera, S. A. et al. 2016. Land-use change affects water recycling in Brazil' $s$ last agricultural frontier. Global Change Biology 22, 3405-3413.

Souza-Filho, P. W. M. et al. 2016. Four decades of land-cover, land-use and hydroclimatology changes in the Itacaiúnas River watershed, southeastern Amazon. Journal of Environmental Management 167, p. 175-184.
Souza G.C., Zanella L, Borém R.A.T., Carvalho L.M.T., Alves H.M.R., Volpato MML. 2014. Análise da fragmentação florestal da Área de Proteção Ambiental Coqueiral, Coqueiral - MG. Ciência Florestal 24, 631-644. http://dx.doi. or/g10.5902/1980509815743.

Volatão, C. F. S. 1998. Trabalho de análise espacial: Métricas do Fragstats. INPE: São José dos Campos.

Wilk, J.; Andersson, L.; Plermkamon, V. Hydrological impacts of forest conversion to agriculture in large river basin in Thailand. Hydrological Processes 15, 2729-2748. . 1979. Land Evaluation and Landscape Science. Enschede: International Institute for Aerial Survey and earth Sciences. 